\title{
Surface-subsurface flow modeling with path-based runoff routing, boundary condition-based coupling, and assimilation of multisource observation data
}

\author{
M. Camporese, ${ }^{1}$ C. Paniconi, ${ }^{2}$ M. Putti, ${ }^{3}$ and S. Orlandini ${ }^{4}$ \\ Received 21 October 2008; revised 2 September 2009; accepted 16 September 2009; published 13 February 2010.
}

[1] A distributed physically based model incorporating novel approaches for the representation of surface-subsurface processes and interactions is presented. A path-based description of surface flow across the drainage basin is used, with several options for identifying flow directions, for separating channel cells from hillslope cells, and for representing stream channel hydraulic geometry. Lakes and other topographic depressions are identified and specially treated as part of the preprocessing procedures applied to the digital elevation data for the catchment. Threshold-based boundary condition switching is used to partition potential (atmospheric) fluxes into actual fluxes across the land surface and changes in surface storage, thus resolving the exchange fluxes, or coupling, between the surface and subsurface modules. Nested time stepping allows smaller steps to be taken for typically faster and explicitly solved surface runoff routing, while a mesh coarsening option allows larger grid elements to be used for typically slower and more compute-intensive subsurface flow. Sequential data assimilation schemes allow the model predictions to be updated with spatiotemporal observation data of surface and subsurface variables. These approaches are discussed in detail, and the physical and numerical behavior of the model is illustrated over catchment scales ranging from 0.0027 to $356 \mathrm{~km}^{2}$, addressing different hydrological processes and highlighting the importance of describing coupled surfacesubsurface flow.

Citation: Camporese, M., C. Paniconi, M. Putti, and S. Orlandini (2010), Surface-subsurface flow modeling with path-based runoff routing, boundary condition-based coupling, and assimilation of multisource observation data, Water Resour. Res., 46, W02512, doi:10.1029/2008WR007536.

\section{Introduction}

[2] Water-driven interactions between the atmosphere, the land surface (including water bodies), and the subsurface are increasingly relevant in water management, ecology, and climate studies [e.g., Winter et al., 1998; Woessner, 2000; Sankarasubramanian et al., 2001]. Surface-subsurface interactions have been investigated over a range of scales, from hillslope and streambed [e.g., Harvey and Bencala, 1993; Fan and Bras, 1998; Storey et al., 2003] to river and watershed [e.g., Nikolaidis et al., 1993; Michaud and Sorooshian, 1994; Blasch et al., 2006]. Nevertheless, there are important unresolved issues in hydrology concerning the differences in response between hillslopes, catchments, and river networks. These issues touch on, for instance, the relative dominance or contributions of overland, channel, and subsurface flow, the relationships between nonlinearity,

\footnotetext{
${ }^{1}$ Dipartimento di Ingegneria Idraulica, Marittima, Ambientale e Geotecnica, Università degli Studi di Padova, Padua, Italy.

${ }^{2}$ Centre Eau, Terre et Environnement, Institut National de la Recherche Scientifique, Université du Québec, Quebec City, Quebec, Canada.

${ }^{3}$ Dipartimento di Metodi e Modelli Matematici per le Scienze Applicate, Università degli Studi di Padova, Padua, Italy.

${ }^{4}$ Dipartimento di Ingegneria Meccanica e Civile, Università degli Studi di Modena e Reggio Emilia, Modena, Italy.
}

Copyright 2010 by the American Geophysical Union. 0043-1397/10/2008WR007536\$09.00 variability, and scale, and the existence or not of thresholds that mark the transition from hillslope to channel-type response [e.g., Rinaldo et al., 1991; Robinson et al., 1995; Seyfried and Wilcox, 1995; Giannoni et al., 2005]. Several studies using restrictive assumptions (e.g., linearized and steady state models, homogeneous parameters and inputs, simplified treatment of boundary conditions) have been conducted to investigate these questions, but studies with more realistic, fully coupled models are also needed. This need is also reflected in the consideration being given recently to groundwater storage and fluxes in both largescale land surface and climate models and smaller-scale infiltration and drainage models [e.g., Yeh and Eltahir, 2005; Koussis et al., 1998; Levine and Salvucci, 1999; Milly and Wetherald, 2002; Nachabe, 2002; Fan et al., 2007].

[3] Quite different modeling approaches are typically used at small (hillslope to catchment) and large (river basin to continental) scales. Our focus here is on the finer scale, where detailed process-based distributed-parameter numerical models, which are computationally demanding and data intensive, are a viable and common approach [Kampf and Burges, 2007; Furman, 2008]. These models numerically resolve the nonlinear partial differential equations for conservation of mass and momentum over the flow region of interest. At larger scales, conceptual models that rely on simplifying the governing equations, parameter distributions, and boundary conditions are more often used. It should be 
noted however that the distinctions between "processbased" and "conceptual" models, in terms of both mathematical formulation and scale of application, are becoming blurrier, as evidenced from recent models that employ elements of both approaches [e.g., Reggiani et al., 1999; Ivanov et al., 2004; Rigon et al., 2006; Qu and Duffy, 2007] and from recent studies such as the distributed model intercomparison project [Smith et al., 2004].

[4] Several process-based numerical models for the simulation of coupled surface and subsurface flow have emerged in recent years. Examples include Pohll et al. [1996], who loosely coupled a 2-D (radial plus vertical) subsurface model to a kinematic runoff routing scheme in a study of seepage beneath a nuclear subsidence crater in Nevada; Singh and Bhallamudi [1998], who coupled a 2-D Richards equation and a 1-D de Saint-Venant equation in a study of overland flow triggering and dynamics on sloping aquifers; Graham and Butts [2005], whose physically based model integrates the de Saint-Venant surface equation to a vertical 1-D Richards equation for unsaturated flow and a 3-D finite element solver for saturated flow; Gunduz and Aral [2005], who focused on the interactions between rivers and aquifers; VanderKwaak and Loague [2001], Morita and Yen [2002], Panday and Huyakorn [2004], and Jones et al. [2008], whose coupling of Richards equation and various approximations of the de Saint-Venant equation relies on the hypothesis of firstorder diffusive exchange of water between surface and subsurface and a finite thickness interface layer; Ababou and Trégarot [2002] and Weill et al. [2009], who developed models based on generalizations of the Darcy-Richards equation that allow implicit coupling between surface and subsurface; Downer and Ogden [2003], who coupled a 2-D Hortonian model with a vertical 1-D Richards equation solver; Anderson [2005], who proposed a Dupuit model of groundwater-surface water interactions; and Kollet and Maxwell [2006], whose coupling approach is based on continuity of pressure head and fluxes at the ground surface.

[5] Standard features of detailed process-based hydrological models include: finite element, finite difference, or finite volume spatial discretizations, often starting from a cellbased representation of the surface topography (e.g., a digital terrain map); sophisticated numerical algorithms for linearizing and solving large systems of equations; handling of nonuniform and heterogeneous parameters and input, when the data for doing so are available; and accommodation of general domain boundaries, with a variety of boundary conditions over this domain. These characteristics will not be described in any detail here; this paper will focus instead on some novel features, summarized below, of a coupled surface-subsurface flow model.

[6] The surface module of the proposed coupled model includes a detailed digital elevation model (DEM) analysis for identification of the drainage network, as well as a procedure for incorporation of retardation and storage effects due to lakes and other topographic depressions. Cell drainage directions can be identified by the simple D8 scheme or by more recent nondispersive and dispersive methods. The diffusion wave equation is used to describe both hillslope (rivulet) flow and stream channel flow, with a different parameterization for these two elements of surface runoff. The distinction between grid cells belonging to the hillslope and stream network systems can be made according to three different threshold-based options, using upstream drainage area, drainage area plus local terrain slope, or gradient divergence normalized by mean gradient criteria.

[7] Coupling between the surface and subsurface flow modules is based on an extension of a boundary condition switching procedure used in some subsurface models for the handling of atmospheric inputs on the surface boundary of the catchment. The coupled model extension incorporates ponding heads at the surface into this procedure, so that potential (atmospheric) fluxes get partitioned into actual fluxes across the land surface and changes in surface storage.

[8] Sequential assimilation of multisource observation data is incorporated via two different schemes: Newtonian nudging and ensemble Kalman filtering, the former simple but somewhat empirical, the latter theoretically rigorous but computationally intensive. Other features of the model exploit the different dynamics of surface and subsurface flow, with an option for generating a coarsened grid for the subsurface domain and the utilization of nested time stepping for the surface module. The model also includes a formulation of the subsurface storage coefficient with moisture-dependent porosity, in order to account for swelling and shrinking soils.

[9] The model's behavior is demonstrated through six applications highlighting different aspects of surface-subsurface interactions. The first two applications deal with a simple synthetic catchment containing a lake and with three hillslopes of different geometry. The other applications concern real catchments of size $4.64,111$, and $356 \mathrm{~km}^{2}$ that are characterized by complex morphology, extensive natural surface depressions, and regional heterogeneity, respectively. The last application features a 3.4 ha headwater of the Vauz River basin located in the eastern Italian Alps, for which extensive data of streamflow, water table, and soil moisture are available.

\section{Model Description}

[10] The Catchment Hydrology (CATHY) model couples a finite element solver for the Richards equation describing flow in variably saturated porous media [Paniconi and Wood, 1993; Paniconi and Putti, 1994] and a finite difference solver for the diffusion wave equation describing surface flow propagation throughout a hillslope and stream channel network identified using terrain topography and the hydraulic geometry concept [Orlandini and Rosso, 1996, 1998]. The mathematical model is described by a system of two partial differential equations:

$$
\begin{gathered}
S_{w} S_{s} \frac{\partial \psi}{\partial t}+\phi \frac{\partial S_{w}}{\partial t}=\nabla \cdot\left[K_{s} K_{r}\left(\nabla \psi+\eta_{z}\right)\right]+q_{s s} \\
\frac{\partial Q}{\partial t}+c_{k} \frac{\partial Q}{\partial s}=D_{h} \frac{\partial^{2} Q}{\partial s^{2}}+c_{k} q_{s}
\end{gathered}
$$

where in the subsurface flow equation (1a) $S_{w}=\theta / \theta_{s}$ is water saturation, $\theta$ is the volumetric moisture content (dimensionless], $\theta_{s}$ is the saturated moisture content (generally equal to the porosity $\phi), S_{S}$ is the aquifer specific storage coefficient $\left[L^{-1}\right], \psi$ is pressure head $[L], t$ is time $[T], \nabla$ is the gradient operator $\left[L^{-1}\right], K_{s}$ is the saturated hydraulic conductivity tensor $[L / T], K_{r}(\psi)$ is the relative hydraulic conductivity 
function [dimensionless], $\eta_{z}=(0,0,1)^{\prime}, z$ is the vertical coordinate directed upward $[L]$, and $q_{s s}$ represents distributed source (positive) or sink (negative) terms $\left[L^{3} / L^{3} T\right]$. In the surface flow equation (1b) a $1-\mathrm{D}$ coordinate system $s[L]$ is used to describe each element of the channel network. In this equation, $Q$ is the discharge along the rivulet/stream channel $\left[L^{3} / T\right], c_{k}$ is the kinematic celerity $[L / T], D_{h}$ is the hydraulic diffusivity $\left[L^{2} / T\right]$, and $q_{s}$ is the inflow (positive) or outflow (negative) rate from the subsurface to the surface $\left[L^{3} / L T\right]$.

[11] The 3-D Richards equation is solved numerically by Galerkin finite elements in space using tetrahedral elements and linear basis functions, and by a weighted finite difference scheme for integration in time. The nonlinear characteristic relationships $K_{r}(\psi)$ and $S_{w}(\psi)$ are specified using either van Genuchten and Nielsen [1985], Brooks and Corey [1964], or Huyakorn et al. [1984] expressions. Linearization via Newton or Picard iteration is used in the solution procedure. More details on the numerical aspects and other features of the subsurface solver can be found in the work by Paniconi and Putti [1994, and references therein].

\subsection{Path-Based Surface Runoff Routing}

[12] Surface hydrologic response in CATHY is determined by the two processes of hillslope and channel flow, operating across all the hillslopes and stream channels forming a drainage basin, and includes storage and retardation effects in streams, pools, and lakes and infiltration/exfiltration effects from subsurface soils.

[13] The surface runoff model aims to reproduce the phenomenology described by Raudkivi [1979, pp. 170 and 171]. According also to Emmett [1978] and Li et al. [1980], surface runoff over hillslope or agricultural watersheds occurs as sheet flow especially at the beginning of rainfall events, prior to concentrating into a series of small channels formed due to topographic irregularities or differences in soil erodibility. It is therefore assumed that the essential features of hillslope flow can be described by considering an accurate representation of surface flow paths extracted from DEM data and the variations of flow characteristics along these paths that conform with the concept of hydraulic geometry introduced by Leopold and Maddock [1953]. The assumption of rill flow fits well with DEM-based network analysis, allowing at the same time lumping of the rill formations into a single conceptual channel at the DEM elemental scale. Onedimensional rivulet flow routing along a network of surface flow paths is preferred over 2-D sheet flow routing since the former ensures a better control of planar dispersion of flow and thus a higher level of consistency with the concept of drainage area [Moretti and Orlandini, 2008; Orlandini and Moretti, 2009a].

[14] The drainage system topography and composition are described by automatically extracting a conceptual drainage network from the catchment DEM. Flow directions are assigned using either the classical D8 scheme [O'Callaghan and Mark, 1984; Marks et al., 1984], the multiple-direction $\mathrm{D} \infty$ method [Tarboton, 1997], or the more recent nondispersive D8-LTD scheme [Orlandini et al., 2003; Orlandini and Moretti, 2009a, 2009b]. The algorithm that incorporates these drainage direction methods requires three preliminary operations, in which (1) the DEM cells of the catchment are sorted into descending elevation order, (2) a recursive procedure is used to raise the elevations of the cells located in flat or depressed areas so as to ensure a drainage direction with a small positive slope (downward) for all the cells of the catchment, and (3) DEM cells are sorted again into descending elevation order. The D8, D8-LTD, or D $\infty$ method can then be applied to form the drainage network and to calculate the drainage areas. DEM cells are processed in the order of descending elevation. Upstream drainage areas are summed up over all the drained cells.

[15] The distinction between hillslope and channel flow can be based on three criteria, by posing a threshold on (1) the upstream drainage area $A$ [e.g., Montgomery and FoufoulaGeorgiou, 1993], (2) the function $A S^{k}, S$ being the local terrain slope and $k$ an exponent [Montgomery and Dietrich, $1988,1989]$, or (3) the gradient divergence normalized by mean gradient (land surface curvature divided by the mean terrain slope) [Howard, 1994]. Using for instance the criterion (1), rill flow is assumed to occur for all those cells for which the upstream drainage area $A\left[L^{2}\right]$ does not exceed the threshold value $A_{t}\left[L^{2}\right]$, while channel flow is assumed to occur for all those cells for which $A$ equals or exceeds $A_{t}$. The option to explicitly define channel head locations is also included in the model.

[16] The dynamic scaling of channel geometry on this quasi-two-dimensional network extracted from grid-based data allows a physically realistic description of surface flow phenomena. Each elemental hillslope rill and network channel is assumed to have bed slope and length that depend on location within the extracted transport network, and a cross section whose resistance/conductance coefficient and watersurface width varies dynamically with discharge according to the scaling properties of stream geometry as described by the "at-a-station" and "downstream" relationships first introduced by Leopold and Maddock [1953]. Variable hillslope flow conditions are therefore described through the proposed surface runoff model, ranging from a network of tiny rivulets to a system of wide rivulets forming essentially a sheet flow. It is acknowledged here that the determination of threshold conditions for channel initiation and the hydraulic characterization of surface flow paths are subject to resolution effects that need to be comprehensively investigated in future studies.

[17] A routing scheme developed on the basis of the Muskingum-Cunge method with variable parameters is used to describe both hillslope rill and channel network flows, with different distributions of hydraulic geometry parameters to take into account the different characteristics of the two hydrologic processes [Orlandini and Rosso, 1998; Orlandini, 2002]. The model routes surface runoff downstream from the uppermost DEM cell in the basin to the outlet, following the previously determined drainage network. A given grid cell will receive water from its upslope neighbors and discharge water to one (in the case of the D8 and D8-LTD single-direction algorithms) or two (in the case of the $\mathrm{D} \infty$ multiple-direction algorithm) downslope neighbors, and it will also receive or release water internally, i.e., from the subsurface. The subsurface contribution is given by the term $q_{s}$ in equation ( $\left.1 \mathrm{~b}\right)$, and it represents the total flux of water per unit length of channel link (i.e., dimensions $\left[L^{3} / L T\right]$ ) that cannot infiltrate to or that actually exfiltrates from the subsurface and that needs to be routed by the surface module. This contribution is determined by the boundary condition switching procedure described in section 2.3. 
[18] Incoming discharges and internal (subsurfacederived) flows are routed into each individual channel via the advection-diffusion flow equation (1b), solved numerically by the Muskingum-Cunge method to yield

$$
Q_{i+1}^{k+1}=C_{1} Q_{i}^{k+1}+C_{2} Q_{i}^{k}+C_{3} Q_{i+1}^{k}+C_{4} q_{s_{i+1}}^{k},
$$

where $Q_{i+1}^{k+1}$ is discharge $\left[L^{3} T^{-1}\right]$ at network point $(i+1) \Delta s$ and time $(k+1) \Delta t, q_{s_{i+1}}^{k}$ is the subsurface contribution at the $(i+1)$ th space interval and time $k \Delta t$, and the routing coefficients $C_{1}, C_{2}, C_{3}$ [dimensionless], and $C_{4}[L]$ depend on $c_{k}$, on the temporal interval $\Delta t$, on the cell channel length $\Delta s$, and on $X$, a weighting factor first introduced by Cunge [1969] for discretizing the kinematic flow equation, i.e., equation (1b) without the diffusive term [Ponce, 1986; Orlandini and Rosso, 1998]. In the current implementation $X$ is used to match the numerical diffusion coefficient of the scheme to the hydraulic diffusivity $D_{h}$ determined by Hayami [1951]. For this reason the Muskingum-Cunge method may also be referred to as a matched artificial dispersivity (MAD) scheme [Syriopoulou and Koussis, 1991; Bajracharya and Barry, 1997]. According to this formulation the kinematic celerity and hydraulic diffusivity are expressed as

$$
c_{k}=\frac{5}{3 G} k_{S}(A, 1)^{3 / 5} W(A, 1)^{-2 / 5} S_{0}^{3 / 10} Q^{1-3 G / 5}
$$

and

$$
D_{h}=\frac{Q^{1-b^{\prime}} \cos \beta}{2 G W(A, 1) S_{0}},
$$

respectively, where $G=1-y^{\prime}+2 / 3 b^{\prime}, y^{\prime}$ and $b^{\prime}$ [dimensionless] being at-a-station hydraulic geometry exponents for the Gauckler-Strickler (GS) conductance coefficient and water-surface width, respectively.

$[19] k_{S}(A, 1)\left[\begin{array}{lll}L^{1 / 3-3} y^{\prime} & T^{y^{\prime}-1}\end{array}\right]$ and $W(A, 1)\left[\begin{array}{lll}L^{1-3} & b^{\prime} & T^{b^{\prime}}\end{array}\right]$ are variable scaling coefficients for the GS coefficient and water-surface width depending on location in the river network, $S_{0}=\sin \beta$ is the channel bed slope, and $\beta$ is the channel bed inclination angle [Orlandini and Rosso, 1998; Orlandini, 2002]. They denote the GS coefficient and the water-surface width at a site draining area $A$ for a flow discharge equal to unity, and are given by

$$
k_{S}(A, 1)=k_{S}\left(A_{s}, Q_{f}\right) Q_{f}\left(A_{S}\right)^{-y^{\prime}}\left(A / A_{S}\right)^{w\left(y^{\prime \prime}-y^{\prime}\right)}
$$

and

$$
W(A, 1)=W\left(A_{s}, Q_{f}\right) Q_{f}\left(A_{S}\right)^{-b^{\prime}}\left(A / A_{S}\right)^{w\left(b^{\prime \prime}-b^{\prime}\right)},
$$

where $k_{S}\left(A_{s}, Q_{f}\right)\left[L^{1 / 3} T^{-1}\right]$ and $W\left(A_{s}, Q_{f}\right)[L]$ are the GS coefficient and the water surface width, respectively, at a selected site $(s)$ with upstream drainage area $A_{s}\left[L^{2}\right]$ and for a flow discharge $Q_{f}\left[L^{3} / T\right]$ with selected frequency $(f)$, and $w$ [dimensionless] is the exponent of the fluvial relationship between discharges $Q_{f}$ of selected frequency and drainage area $A$ [Leopold et al., 1964, p. 251]. The exponents $y^{\prime}, y^{\prime \prime}$, $b^{\prime}, b^{\prime \prime}$, and $w$ are characteristics of the rill/stream channel network as a whole, and characterize the "at-a-station" and "downstream" relationships of [Leopold and Maddock, 1953] (see Appendix A). When field measurements are not available to characterize rill flow dynamics, geometry and roughness parameters can be empirically evaluated from literature studies [e.g., Parsons et al., 1994; Abrahams et al., $1996]$.

[20] When the runoff routing equation has been solved, the updated incoming and outgoing discharges at each cell are known, and from this information the cell water depth, or ponding head $h$, can be determined from simple mass balance considerations. These heads represent positive pressure heads $\psi$ at the surface and form part of the surface boundary condition for the next call to the subsurface solver.

\subsection{Lake Handling}

[21] Isolated topographic depressions ("pits") in the catchment DEM can be attributed to the presence of pools or lakes, or can be interpreted as erroneous or missing data. Depressions cannot be handled by automatic drainage network extraction procedures, and depitting techniques are generally used to modify the elevation values and to regularize the DEM. These depitting schemes correct DEM errors and can also be used in steep basins, where the flow is mainly driven by slope and where slight artificial modifications of topography will not significantly change surface flow patterns. However, when depressions play an important role in the formation of surface and subsurface fluxes these procedures introduce inconsistent flow directions and do not correctly reproduce the storage and retardation effects of pools and lakes on the catchment response. This typically happens in relatively flat areas where flow patterns are strongly influenced by small slope changes.

[22] In this work the location of the topographic depressions is identified from the DEM and from prior field information. A "lake boundary-following" procedure [Mackay and Band, 1998] is employed to isolate and correct for potential breakdown in the subsequent drainage network extraction process. In this procedure, each cell along the boundary of the pit (also called "buffer cells") acts as a depression point for all the catchment cells draining into the pit. To ensure correct flow paths in the area, the drainage direction in all the buffer cells is forced to form a circulation path that drains into a single cell (the lake outlet or "reservoir" cell). A flow path algorithm, in combination with a "slope tolerance" based correction procedure to account for the remaining erroneous depressions, is then applied to the modified DEM that excludes the central cells of the depression. The storage and retardation effects of the pit are accounted for by transferring with infinite celerity all the water drained by the buffer cells to the lake outlet cell, which is now treated as a reservoir. All the geometrical and physical characteristics of the depression are thus attributed to this cell. Outflow from this cell is calculated by solving, by a level pool routing procedure, the continuity equation for the reservoir:

$$
\frac{d V}{d t}=I(t)-O\left(h^{*}\right)
$$

where $V$ is the storage volume of the reservoir and $I$ and $O$ are the incoming and outgoing discharges, functions of time and of water elevation $h^{*}$ (above a reference level) in the reservoir, respectively. The reservoir water elevation thus 
determined is then assigned to all the lake cells and used in the subsurface solver as ponding head, while the discharge from the reservoir is the outgoing flux at the cell to be used in the surface routing.

\subsection{Boundary Condition-Based Coupling}

[23] The source/sink terms $q_{s s}$ and $q_{s}$ in equations (1a) and (1b), respectively, represent the exchange of water between the surface and subsurface flow regimes. The surface-tosubsurface contribution, $q_{s s}$, or its equivalent in ponding head $h$, is determined after solving the surface routing equation (1b) for subsequent input to the subsurface flow equation (1a), while the subsurface-to-surface contribution, $q_{s}$, is determined after solving the subsurface equation for subsequent input to the surface equation. The noniterative sequential procedure for the solution of the coupled equations is described in section 2.5. Conversions between total or volumetric flux $\left(\left[L^{3} / T\right]\right)$, specific flux $([L / T])$, and ponding head $([L])$ are readily performed by invoking time step size and surface area attributions for cells and nodes (cell/node correspondences are described in section 2.6). For instance, as described in section 2.1, after solving the surface routing equation, ponding heads are obtained from a simple mass balance calculation. Invoking step size and nodal areas converts these to volumetric fluxes, and volume integration in the Galerkin finite element procedure produces the required dimension of $\left[L^{3} / L^{3} T\right]$ for $q_{s s}$. At the end of the subsurface time step, volumetric fluxes to be passed to the surface module are produced at each node based on the boundary condition switching procedure described below. Dividing by nodal areas and multiplying by cell areas converts these to volumetric fluxes at each cell, and invoking the channel element length for each cell produces the required dimension of $\left[L^{3} / L T\right]$ for $q_{s}$.

[24] Notwithstanding the role of the surface module in resolving the surface-subsurface exchanges, it is the subsurface module that exercises more control over the coupling process. This is because atmospheric forcing, a key term in surface-subsurface partitioning, is handled, as a special-case boundary condition, by the subsurface equation. This handling is an extension of the way atmospheric inputs are commonly treated in variably saturated subsurface flow models [e.g., Freeze, 1971; Huyakorn et al., 1986; Paniconi and Wood, 1993]. It is a special-case treatment because the boundary condition for any given surface node can switch between a Dirichlet condition and a Neumann condition, depending on the saturation (or pressure) state of that node. A Neumann (or specified flux) boundary condition corresponds to atmosphere-controlled infiltration or exfiltration, with the flux equal to the rainfall or potential evaporation rate given by the atmospheric input data. When, during prolonged or intense periods of rainfall or evaporation the surface node reaches a threshold level of saturation or moisture deficit, the boundary condition is switched to a Dirichlet (specified head) condition, and the infiltration or exfiltration process becomes soil limited.

[25] In the coupled model extension of this switching algorithm [Bixio et al., 2000], ponding status is incorporated into the procedure. Thus the algorithm flags each surface node according to whether it is currently ponded, saturated, below saturation, or air-dry. The distinction between a surface node or cell being saturated or ponded is made by introducing an input parameter that represents the threshold pressure head (or ponding) value a surface node must attain before water can be routed by the surface flow module. This parameter can account, for example, for the amount of water that remains trapped in microtopographic features of the surface.

[26] In the case of rainfall, unsaturated surface nodes that have become saturated or ponded are assigned a fixed head (Dirichlet) boundary condition, and in the subsequent iteration or time step of the subsurface flow module the soillimited infiltration or return flow rate is calculated by the code after obtaining the pressure head solution. In the case of evaporation, an unsaturated surface node that has become saturated or ponded is assumed to represent subsurface return flow and is switched to soil-limited (Dirichlet) mode for subsequent surface flow routing.

[27] In the case of rainfall, a saturated or ponded Dirichlet surface node is switched to Neumann mode whenever the model-computed flux exceeds the input potential rate, a signal for example that the rainfall rate has fallen below the infiltration capacity of the soil. Note that there is thus no switching in the case of return flow (negative flux). The case of evaporation again presents a situation where subsurface return flow is possible, and a saturated or ponded Dirichlet surface node is switched to an atmospheric flux condition only if the model-computed flux is positive (infiltration) or, if it is negative, its absolute value, including the ponding head contribution, is smaller than the absolute value of the potential evaporation rate. No switching is done if the modelcomputed flux is negative and its absolute value, including the ponding head contribution, is larger than the potential rate, since in this situation there is return flow in excess of atmospheric demand that will contribute to ponding.

[28] The case of evaporation is considered to be analogous to the threshold behavior that occurs during rainfall when the surface becomes saturated or ponded. When the surface soil reaches a moisture deficit threshold, parameterized by its corresponding pressure head level $\left(\psi_{\text {min }}\right)$, the boundary condition switches from Neumann to Dirichlet, and the evaporation (exfiltration) process becomes soil limited. $\psi_{\text {min }}$ can be interpreted as the "air-dry" value for that soil [e.g., Hollinger and Isard, 1994], and the switching point represents the advent of stage two evaporation [Salvucci, 1997]. An air-dry Dirichlet node switches back to a Neuman condition when it begins to rain, or, under evaporation conditions, when the absolute value of the model-computed flux becomes larger than the absolute value of the input potential rate.

[29] Having determined the updated saturation or pressure state of each surface node, and knowing for each of these nodes whether the potential atmospheric forcing is positive (rainfall) or negative (evaporation) and, in the case of a Dirichlet boundary condition, whether the actual, modelcomputed flux represents infiltration or exfiltration and also its absolute value relative to the potential flux, the inflow terms $q_{s}$ to be passed to the surface flow routing module for the next time step are established. The boundary condition switching procedure thus partitions potential (atmospheric) fluxes into actual fluxes across the land surface (infiltration, exfiltration as evaporation, and exfiltration as return flow) and changes in surface storage (ponding heads).

[30] The exchange of flux and ponding head information performed via the switching algorithm in the subsurface 
module and the simple mass balance calculation in the surface module resolves the coupling in the CATHY model, and does so without the need to introduce new parameters representing an exchange process or an interface property. This procedure is quite different, therefore, from the approach used in other coupled models [e.g., VanderKwaak and Loague, 2001; Morita and Yen, 2002; Panday and Huyakorn, 2004], but still guarantees the necessary continuity of flux and pressure head at the ground surface [Kollet and Maxwell, 2006].

[31] Note that in case of simultaneous precipitation and evaporation, we impose at the surface the net flux, i.e., precipitation minus evaporation. Moreover, during most rainfall events, the evaporation rate is typically one or more orders of magnitude smaller than the precipitation rate.

\subsection{Assimilation of Multisource Observation Data}

[32] Data assimilation (DA) allows model simulations to be updated with observation data. More advanced DA methods also provide a framework for incorporating model and data errors and for quantifying prediction uncertainties. The data assimilation schemes implemented in the coupled model are dynamical relaxation (also known as Newtonian nudging) and the ensemble Kalman filter (EnKF). The use of EnKF is becoming common in land surface hydrological modeling for very large scale applications [e.g., Margulis et al., 2002; Crow and Wood, 2003] and for conceptual rainfall-runoff modeling [e.g., Clark et al., 2008], but is largely unexplored in process-based numerical modeling at catchment and smaller scales. Nudging, which is a simple special case of a Kalman filter, was implemented as a first DA scheme in a 3-D numerical Richards equation-based model [Paniconi et al., 2003b]. Subsequent to this work, the ensemble Kalman filter was added to the model [Camporese et al., 2009a], including in this implementation also the possibility to assimilate observations from different sources, both surface and subsurface.

[33] In nudging, state variables are driven toward observations by adding a forcing term to the model equation. In our implementation Richards' equation is extended to

$$
\begin{aligned}
S_{w} S_{s} \frac{\partial \psi}{\partial t}+\phi \frac{\partial S_{w}}{\partial t}= & \nabla \cdot\left[K_{s} K_{r}\left(\nabla \psi+\eta_{z}\right)\right]+q_{s s} \\
& +\Gamma \frac{\sum_{k=1}^{N_{T}} \sum_{i=1}^{N_{X}} W_{k i}^{2}(\mathbf{x}, t) \epsilon_{i}\left(\zeta_{o_{k i}}-\zeta_{i}(t)\right)}{\sum_{k=1}^{N_{T}} \sum_{i=1}^{N_{X}} W_{k i}(\mathbf{x}, t)}
\end{aligned}
$$

where $\mathbf{x}=(x, y, z)^{T}$ is the Cartesian spatial coordinate vector, $N_{T}$ is the number of observation times, $N_{X}$ is the number of observation points, $\zeta_{o}$ and $\zeta_{i}$ are the observed and computed values, respectively, of the state variable being assimilated, $\Gamma$ determines the relative strength of the nudging term with respect to the physical forcing term, $W_{k i}(\mathbf{x}, t)$ are weights to be specified as functions of space and time, and $\epsilon_{i} \leq 1$ is a factor that reflects the accuracy of the observation (equal to 1 for perfect measurements). In this general formulation, the state variable being measured and assimilated, $\zeta$, can represent soil moisture $\theta$, pressure head $\psi$, or any other variable. The dimensions of $\Gamma$ need to be adjusted according to the state variable under consideration, for instance $\left[T^{-1}\right]$ when assimilating soil moisture and $\left[L^{-1} T^{-1}\right]$ when assimilating pressure head. Note that the forcing term is proportional to the difference between the actual solution and the observation to be assimilated, and that the weighting functions can incorporate prior knowledge about the spatial and temporal variability and characteristic scales of the state variable being assimilated.

[34] The basic formulation of EnKF is represented by three vector-valued discrete-time equations:

$$
y(t)=A[y(\tau), \alpha, u(t), t, \tau] ; t>\tau \geq 0 ; y_{0}\left(t_{0}\right)=y_{0}(\alpha)
$$

$$
z_{i}=M\left[y, \omega_{i}, t_{i}\right]
$$

$y^{j}\left(t_{i+1} \mid Z_{i+1}\right)=y^{j}\left(t_{i+1} \mid Z_{i}\right)+K_{i+1}\left\{z_{i+1}+\omega_{i+1}^{j}-M\left[y^{j}\left(t_{i+1} \mid Z_{i}\right)\right]\right\}$,

i.e., the model equation, the measurement equation, and the update equation, respectively. The model equation is a statespace representation of the discretized forms of equations (1a) and (1b). The vector $y(t)$, superscript $j$ indicating one realization of the ensemble, contains the uncertain hydrologic states, that in our implementation are pressure head at each node of the subsurface grid and incoming and outgoing discharge at each cell of the surface discretization. The vector $\alpha$ represents the time-invariant set of soil parameters (saturated hydraulic conductivity, specific storage, porosity, retention curve parameters, etc.), while the vector $u(t)$ represents the time-dependent atmospheric forcing variables (precipitation or evaporation). The initial condition at time $t=$ $t_{0}$ is given by $y_{0}(\alpha)$ and the nonlinear operator $A$ describes how the state at a previous time $\tau$ is related to the state at time $t$. The operator $M$ represents the transfer model that describes how the observations are related to the system states, the vector $z_{i}$ contains pressure head and/or soil moisture and/or streamflow data measured at time $t_{i}$, and $\omega_{i}$ is a random noise term that accounts for measurement errors. Finally, the Kalman gain $K_{i+1}$ measures the level of confidence of the model with respect to the measurements. The Kalman gain depends on the system state covariance matrix and the measurement error covariance matrix, both computed by sampling the ensemble statistics.

[35] The inclusion of observation data from various sources in our implementation of EnKF is an important feature since, for small-scale catchment applications, good coverage from point measurements of different state variables is more feasible than in large-scale applications, where remote sensing is the main source of measurements (gridded observations). Thus, for example, a hillslope or catchment may be instrumented such that soil moisture profiles and groundwater levels are measured regularly at a handful of locations, together with outlet streamflow. With EnKF the coupled model needs to be solved for each realization in the ensemble, so its computational costs can be quite higher than for the nudging scheme, although this will also depend on the density of measurement points, which can adversely affect the performance of the nudging method. This and other tradeoffs between the simpler nudging method and the more advanced EnKF are explored by Camporese et al. [2009b]. 


\subsection{Nested Time Stepping}

[36] As reported by Cunge [1969], the Muskingum-Cunge or MAD scheme used by the surface solver is unconditionally stable since the numerical dispersion of the scheme is matched to the hydraulic diffusivity, which is always a positive quantity. Nevertheless, it requires grid and time step constraints to be respected in order to provide accurate results. Specifically, positive coefficients $C_{1}, C_{2}$, and $C_{3}$ ( $C_{4}$ is always positive) in equation (2) are found to ensure accurate and physically meaningful results. Ponce [1986] noted that the condition $C_{1}>0$ is especially important. Accuracy criteria can be expressed in terms of Peclet $(\mathrm{Pe})$ and Courant $(\mathrm{Cu})$ numbers as shown by Syriopoulou and Koussis [1991]. In the present implementation of the surface solver, accurate results are however ensured by simply approximating the condition $C u=1$ through an appropriate selection of the time step sizes. Less restrictive accuracy conditions will be sought in order to allow flexible choices of structural parameters (i.e., grid and step sizes) while conserving accurate representations of hillslope and channel flow processes.

[37] The subsurface solver is implicit in time and is limited by less restrictive accuracy constraints. It is the subsurface solver that controls the time evolution of the simulation using adaptation and "back stepping". The time step size established by this strategy, $\Delta t_{s s}$, is in general larger than that required by the accuracy criterion in the surface routing module, $\Delta t_{s}$. Thus for each subsurface (or "outer") time level, indexed by $k, n_{s}=\operatorname{int}\left(\Delta t_{s s} / \Delta t_{s}\right)$ surface (or "inner") time steps are executed, where $n_{s}$ is recomputed for each new outer time level (since the Courant number is also affected by the $q_{s}$ fluxes determined from the subsurface solver and by the surface dynamics). It should be noted that the value of $n_{s}$ for the current outer time level is based on surface flow discharges from the previous time level, and thus cannot be guaranteed to precisely satisfy the theoretical accuracy criterion. In practice, however, since $C u$ values slightly larger than 1 are also acceptable, this procedure has been found to be satisfactory [Orlandini and Rosso, 1996].

[38] The explicit in time nature of the Muskingum-Cunge discretization scheme allows the construction of the following noniterative sequential algorithm, proceeding from time $t^{k}=0$ to $T_{\max }$, for the solution of equations (1a) and (1b): (1) determine $n_{s}$ from $\Delta t_{s s}$ and $\Delta t_{s}$ and solve equation (1b) $n_{s}$ times using $q_{s}^{k}$ as input to the surface routing module, obtaining $Q^{k+1}$ and from this the distribution of ponding heads $h^{k+1}$ (equivalently, $q_{s s}^{k+1}$ ); (2) use $h^{k+1}$ and atmospheric inputs at time $t^{k+1}$ to set up boundary conditions for the subsurface solver, and solve equation (1a) for $\psi^{k+1}$; (3) calculate (again with the subsurface solver) the inflow term or overland flux $q_{s}^{k+1}$ using $\psi^{k+1}$ and the balance between atmospheric inputs and actual fluxes as per the boundary condition switching procedure. Note that in step (1) both $\Delta t_{s s}$ and $\Delta t_{s}$ are variable, i.e., they are recomputed for each outer time level, via convergence-based time step adaptation for $\Delta t_{s s}[$ [D'Haese et al., 2007] and by applying accuracy constraints as previously described for $\Delta t_{s}$. This strategy automatically adapts to the different timescales of the surface routing and subsurface flow processes, but introduces a constraint on $\Delta t_{s s}$, that needs to be controlled to avoid a too large number of surface times steps per subsurface step. While the experience acquired so far suggests more than $30-$
50 surface time steps may lead to poor mass balances, the theoretical aspects of this constraint need to be further investigated.

[39] The above algorithm needs to be initialized, and this is done by setting an initial condition in terms of flow discharges for equation (1b). If this condition, as often happens, is not known a priori, it can be established from an initial run of the subsurface solver, which will provide a first guess for the overland flow based on the actual atmospheric input. In this case, an initial distribution of $\psi$ needs to be specified. For subsurface solvers, initial pressure heads are commonly set to be uniformly distributed or in vertical hydrostatic equilibrium combined with prior knowledge of the water table position, or they can be generated from a steady state water balance simulation.

\subsection{Mesh Coarsening and Other Grid Issues}

[40] Due to the 1-D nature of the surface flow module versus the 3-D nature of the subsurface module, and the cellbased spatial discretization of the former with respect to the node-based discretization of the latter, some issues arise when exchanging information between the two modules. Moreover, due to the particular algorithm used for handling lakes and depressions, surface routing neglects the cells corresponding to pits, whereas the subsurface solver cannot exclude these zones. For these reasons, appropriate algorithms have been developed for a correct exchange of information between the two modules.

[41] The cell discretization produces two different numberings: a complete one for the subsurface grid, including pit cells, and a partial one for surface discretization, without pit cells. Each cell of the complete surface grid is subdivided into two triangles, which are in turn projected along the vertical to create the 3-D tetrahedral finite element mesh. It is also possible to define a coarsened subsurface grid, i.e., surface cells can be grouped in order to generate two triangles for every $4\left(2^{2}\right)$ cells, or two triangles for every $9\left(3^{2}\right)$ cells, and so forth (Figure 1). In this way the grid resolution for the surface module is maintained while reducing significantly the computational effort for the subsurface solver.

[42] The exchange of information between cells and nodes occurs as follows: ponding heads computed by surface routing on the cells are transferred to the nodes by means of linear interpolation; likewise node-based local contributions to overland flow calculated by the subsurface solver are linearly interpolated and passed to the surface cells. These interpolations are necessary because the nodes of the subsurface grid are positioned at the corners of the cells. Note that for the definition of the boundary conditions to be passed to the subsurface module, an average water depth on the cell is computed by dividing the water volume by the cell area, instead of using the "real" water depth of the 1-D channel inside the cell, which is accurately computed due to the dynamic scaling of the stream network sections. This procedure is necessary in order to correctly transfer the water depths to the surface nodes of the subsurface grid, independently of the channel position inside the cell.

\subsection{Other Model Features}

[43] The coupled model includes a number of other features. Both Dirichlet and Neumann nonatmospheric boundary conditions can be imposed, and these can vary in both time and space. Seepage face boundary conditions, with an 

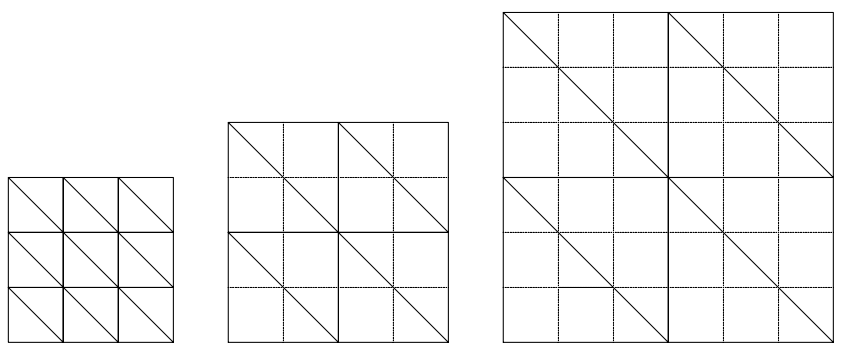

Figure 1. Surface and subsurface gridding: (left) in the default discretization each DEM cell of the surface mesh is divided into two triangles for subsurface discretization; (middle) mesh coarsening options include a 4-to-2 mapping where 4 DEM cells become 2 triangles, (right) a 9-to- 2 mapping where 9 cells become 2 triangles, and so on.

algorithm that searches for the exit point at each time step, are also handled. Once discretized, the model can theoretically accept parameter values and boundary conditions measured at each node or element of the mesh boundary and interior. Even though such detailed observation data is rarely available, the coupled model is capable of taking into account any sort of heterogeneity.

[44] A constitutive relationship that accounts for unsaturated soil swelling and shrinking is also implemented [Camporese et al., 2006a]. This relationship describes the variation of porosity with moisture content and entails a significant modification of the Richards equation storage term (left member of equation (1a)). The variation in the unsaturated zone is added to the contribution of primary consolidation in the saturated zone and used to calculate soil surface elevation change [Camporese et al., 2006b].

\section{Model Applications}

[45] Six applications covering a range of scales from 0.0027 to $356 \mathrm{~km}^{2}$ are presented to illustrate the capability of the model to reproduce a variety of hydrological processes. Each application focuses on a specific physical process and shows how the proposed model can deal with the relevant numerical challenges. The first application is intended to simulate the effects of lake attenuation on watershed streamflow and shows the functioning of the lake handling procedure; the second application deals with hillslope recharge and drainage processes for different shapes, slopes, and boundary conditions; the third application highlights surface-subsurface interactions, and numerical aspects of these interactions, for a real catchment subject to a sharp change from heavy rainfall to evaporation, and it compares the nudging and EnKF data assimilation schemes for a test case with biased atmospheric boundary conditions; the fourth application examines the hydrological response of an arid watershed in Eastern Africa, in particular with respect to the issue of soil-controlled evaporation; the fifth application concerns a large contaminated basin where small surface depressions distributed over the entire region act as preferential infiltration paths; finally, an application to a small headwater located in the eastern Italian Alps provides an evaluation of the model performance comparing real observations with simulated data. It should be stressed that the objective here is not to provide a mere validation of the model, but to give practical examples of the processes and topics examined in section 2 of the paper.
[46] Table 1 summarizes the model discretization, parameter values, and numerical performance for the six applications. With reference to equations (5) and (6), note that for all applications the reference upstream drainage area $A_{s}$ has been set equal to the total catchment area, $w$ has been set to 1 , and $y^{\prime}$ and $y^{\prime \prime}$ have been set to 0 . This implies that the GS coefficient $k_{S}$ is constant in space and time. The D8-LTD option was used for the drainage network extraction in all cases.

\subsection{Small Catchment With Lake}

[47] The domain is represented by the small hypothetical catchment shown in Figure 2, characterized by a depression in its central part with a minimum elevation of $11 \mathrm{~m}$ above the reference plane. Application of the Muskingum-Cunge method to solve the surface routing equation in the depressed cells requires preprocessing with the lake handling algorithm described in section 2.2. The 9 central cells shown in dark grey in Figure 2 are first eliminated from the surface DEM during the drainage network extraction process. In the surrounding "buffer" cells (light grey in Figure 2) the flow direction is imposed so that the water is drained toward the "reservoir" cell (" $\mathrm{R}$ " in Figure 2), in which the geometrical characteristics of the whole depression are concentrated. Water is allowed to flow out from the reservoir when the level rises above $14 \mathrm{~m}$, which is the real elevation of the lowest cell surrounding the depression. A constant value of $10 \mathrm{~m}^{1 / 3} \mathrm{~s}^{-1}$ is assigned to the Gauckler-Strickler conductance coefficient, while the value of ponding head threshold is set to $0.0001 \mathrm{~m}$. The underlying aquifer is assumed to have homogeneous and isotropic hydraulic properties, as reported in Table 1. No-flow conditions are imposed along the vertical boundaries of the 3-D domain, as well as for the bottom layer. Initial conditions were generated by running a steady state simulation with no atmospheric forcing and zero flow boundary conditions along all the other boundaries except for the vertical face containing the outlet cell, for which a hydrostatic pressure head profile corresponding to a water table set at $0.1 \mathrm{~m}$ under the soil surface was imposed. The initial water level in the lake was set to $13.5 \mathrm{~m}$.

[48] The catchment is subject to constant precipitation of intensity $1.0 \times 10^{-5} \mathrm{~m} / \mathrm{s}(36 \mathrm{~mm} / \mathrm{h})$ from $t=0$ until $t=19 \mathrm{~h}$. From $t=19 \mathrm{~h}$ the precipitation rate decreases linearly to zero at $t=20 \mathrm{~h}$. At this time evaporation begins with linearly increasing intensity up to $-1 \times 10^{-6} \mathrm{~m} / \mathrm{s}(86.4 \mathrm{~mm} / \mathrm{d})$ at $t=$ $21 \mathrm{~h}$. From $t=21 \mathrm{~h}$ evaporation continues at constant rate until the end of the simulation at $t=30 \mathrm{~h}$.

[49] The results of the simulation in terms of streamflow at the outlet of the catchment are reported in Figure 3, together with the comparison between the potential atmospheric forcing and the actual soil fluxes integrated by the model over the catchment surface. The catchment surface becomes saturated from the very beginning of the simulation due to infiltration excess (Hortonian runoff), and the streamflow nearly reaches a steady state, before peaking again after the central depression has filled up (from about $16 \mathrm{~h}$ ) and begins contributing to overland flow generation. Note that at the beginning of the simulation as well as during the evaporation phase the actual soil fluxes computed by the model are larger than the potential atmospheric forcing. This is again an effect of the central depression, from which water infiltrates into the soil from the beginning of the rainfall event and even as evaporation occurs. 


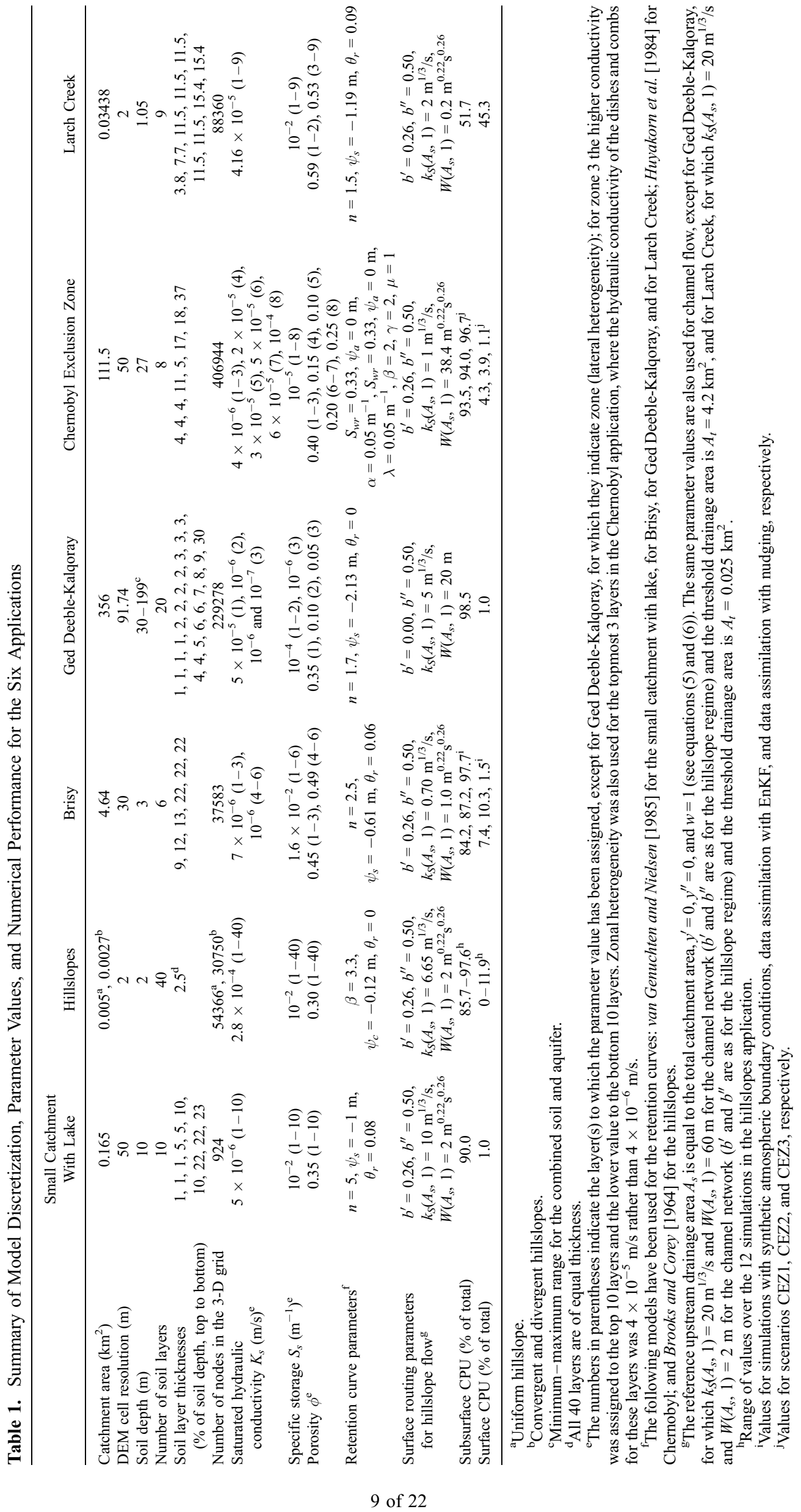




\begin{tabular}{|l|l|l|l|l|l|}
\hline 12 & 11 & 10 & 11 & 12 & 13 \\
\hline 12 & 12 & 12 & 12 & 12 & 13 \\
\hline 13 & 13 & 13 & 13 & 13 & 14 \\
\hline 14 & 14 & 14 & 14 & 14 & 15 \\
\hline 14 & 13 & 13 & 13 & 14 & 15 \\
\hline 13 & 12 & 12 & 12 & 13 & 14 \\
\hline 13 & 12 & 11 & 12 & 13 & 14 \\
\hline 13 & 12 & 12 & 12 & 13 & 14 \\
\hline 14 & 13 & 13 & 13 & 14 & 15 \\
\hline 14 & 14 & 14 & 14 & 14 & 15 \\
\hline 15 & 15 & 15 & 15 & 15 & 15 \\
\hline
\end{tabular}

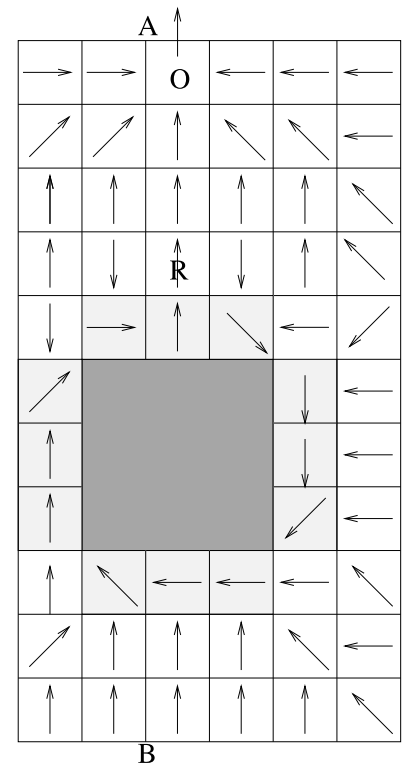

Figure 2. (left) DEM for the small catchment with lake (elevations are in $\mathrm{m}$ asl) and (right) the surface cell flow paths. The interior area of the depression is shown in dark grey and the buffer cells with forced flow directions are shown in light grey. The reservoir cell is identified by " $\mathrm{R}$ " and the outlet cell by "O." "A" and "B" are the endpoint nodes of the transect examined in Figure 4.

[50] The simulation results are also represented in Figure 4, in terms of ponding heads along a transect of nodes passing through the depression. Ponding occurs in the depression almost from the beginning of the simulation, and reaches a maximum value of about $h=2.35 \mathrm{~m}$ in the lowest node of the lake by the end of the precipitation period, to decrease to $h=2.25 \mathrm{~m}$ by the end of the simulation. The maximum ponding head of about $2.35 \mathrm{~m}$ is consistent with the predefined maximum reservoir water level of $14 \mathrm{~m}$ : with the elevation of the lowest node in the depression at $11.67 \mathrm{~m}$, at these values of ponding head, water from the lake spills onto nonlake cells.

[51] By the end of the simulation, exfiltration (the actual flux shown in Figure 3 ) is still only $18 \%$ of the potential atmospheric evaporation rate. This is again due to the large amount of water that remains in the depression, which continues to contribute to infiltration even as most nonlake surface nodes are no longer saturated and are providing water from the soil to satisfy the atmospheric demand. The atmospheric demand from lake nodes, on the other hand, is satisfied directly by ponded water. This water thus contributes simultaneously to both evaporative demand and to infiltration, and the "accounting" performed by the boundary condition switching algorithm correctly resolves these contributions. This test case was set up as a somewhat extreme example so as to illustrate some of these points, with precipitation intensity 10 times greater than evaporation, thus allowing the reservoir to quickly fill and slowly empty, and with a low saturated hydraulic conductivity value (relative to the precipitation rate) that limits infiltration during the rainfall period, thus favoring ponding.

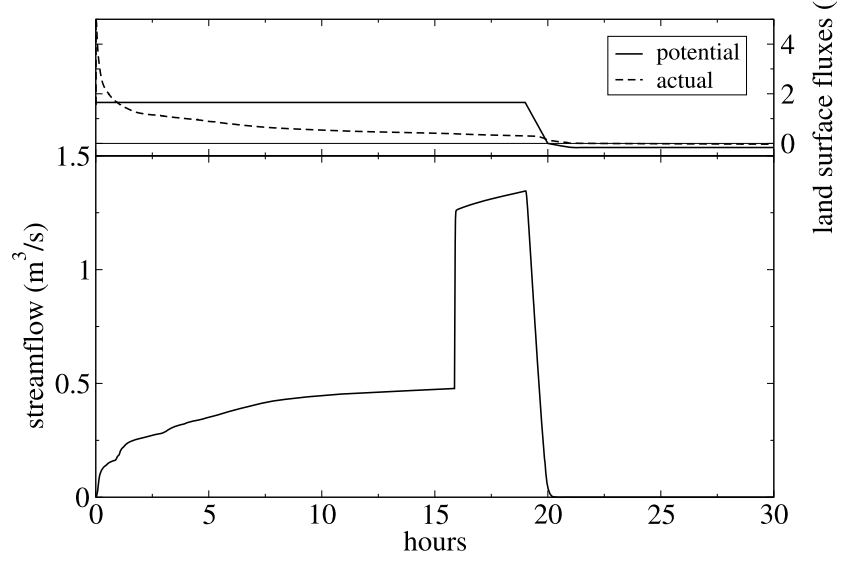

Figure 3. (top) Potential (atmospheric) and actual (modelcomputed) land surface fluxes and (bottom) simulated streamflow at the catchment outlet for the small catchment with lake application. Positive values of land surface flux represent potential precipitation and actual infiltration, while negative values represent potential evaporation and actual exfiltration.

\subsection{Convergent, Uniform, and Divergent Hillslopes}

[52] The coupled model was applied to a set of three sandy loam hillslopes, of convergent, uniform, and divergent plan shape (Figure 5). For each hillslope, two slope values were considered, namely $5 \%$ and $30 \%$, as well as two configurations of the boundary conditions. The soil depth of the hillslopes is constant, so that the slope value is the same for both the bedrock layer and the surface. For all runs vertically hydrostatic initial conditions are used, with the water table $(\psi=0 \mathrm{~m})$ positioned at $0.4 \mathrm{~m}$ above the bedrock, giving a pressure head of $-1.6 \mathrm{~m}$ at the surface and $0.4 \mathrm{~m}$ for the nodes along the base of the hillslope. The atmospheric forcing consists of a constant rainfall rate of $10 \mathrm{~mm} / \mathrm{d}$ $\left(4.167 \times 10^{-1} \mathrm{~mm} / \mathrm{h}\right)$. The hillslope divide at the slope crest is always treated as a no-flow boundary and the lateral

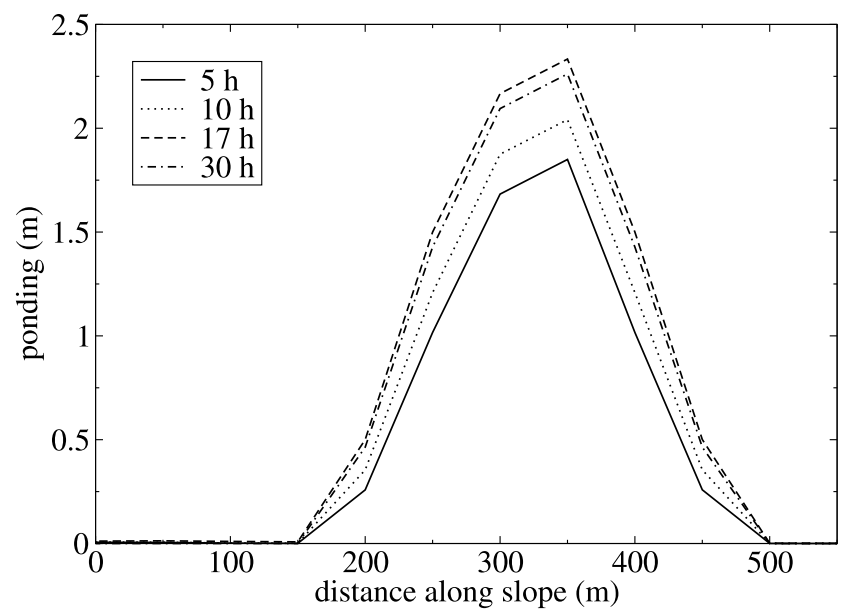

Figure 4. Ponding heads along transect AB (see Figure 2) at $t=5,10,17$, and $30 \mathrm{~h}$ for the small catchment with lake application. 

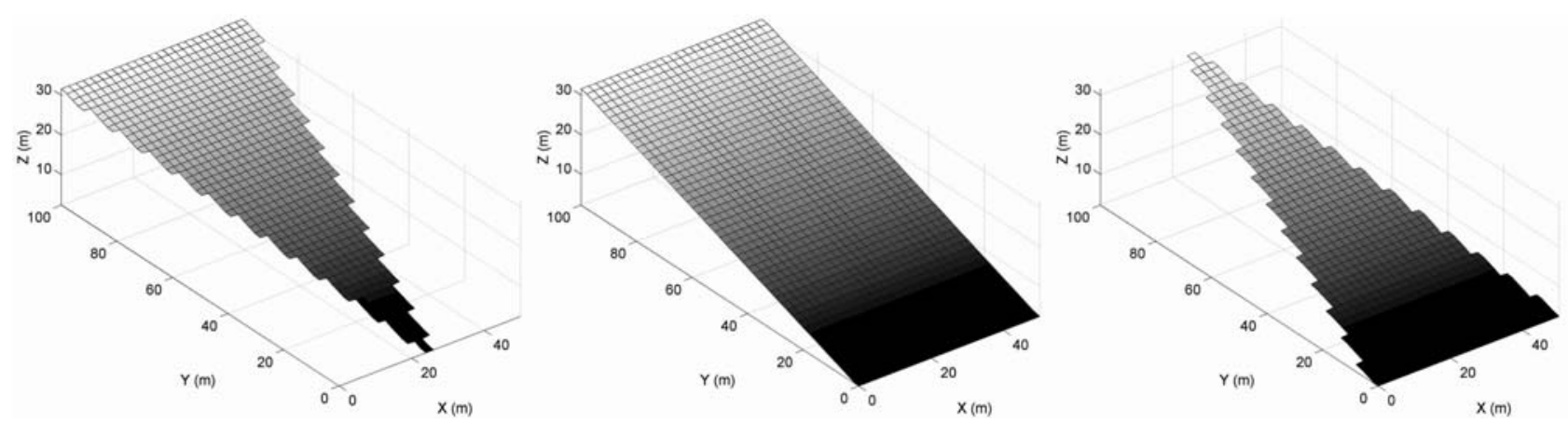

Figure 5. Illustration of the surface and plan shape ((left) convergent, (middle) uniform, and (right) divergent) of the three hillslopes. Figure 5 refers to the $30 \%$ slope case.

divides and the bottom layer are also assigned a no-flow condition. In the first configuration of boundary conditions ("Dirichlet runs"), the outlet nodes at the bottom layer form a constant head boundary of zero pressure head and the nodes above along the outlet face have a no-flow condition imposed. In the second configuration ("return flow runs"), the entire outlet face is a no-flow boundary and water is allowed to leave the system only by exfiltration (return flow) through the surface.

[53] The outflow rates, water table profiles, and ponding head distributions for the set of 12 runs are presented in
Figures 6 (for the Dirichlet configuration) and 7 (for the return flow case). For the Dirichlet runs, the results are comparable to those from a previous subsurface flow study [Paniconi et al., 2003a], with minor differences arising from the different grids used, and with the addition of surface runoff generation and overland flow routing in the current study. In Figure 6 it is observed that overland flow occurs for both the $5 \%$ and $30 \%$ convergent hillslopes, due to return flow generated once the water table reaches the soil surface (with a very high soil conductivity relative to rainfall rate, any surface saturation occurrence in these hillslope applications
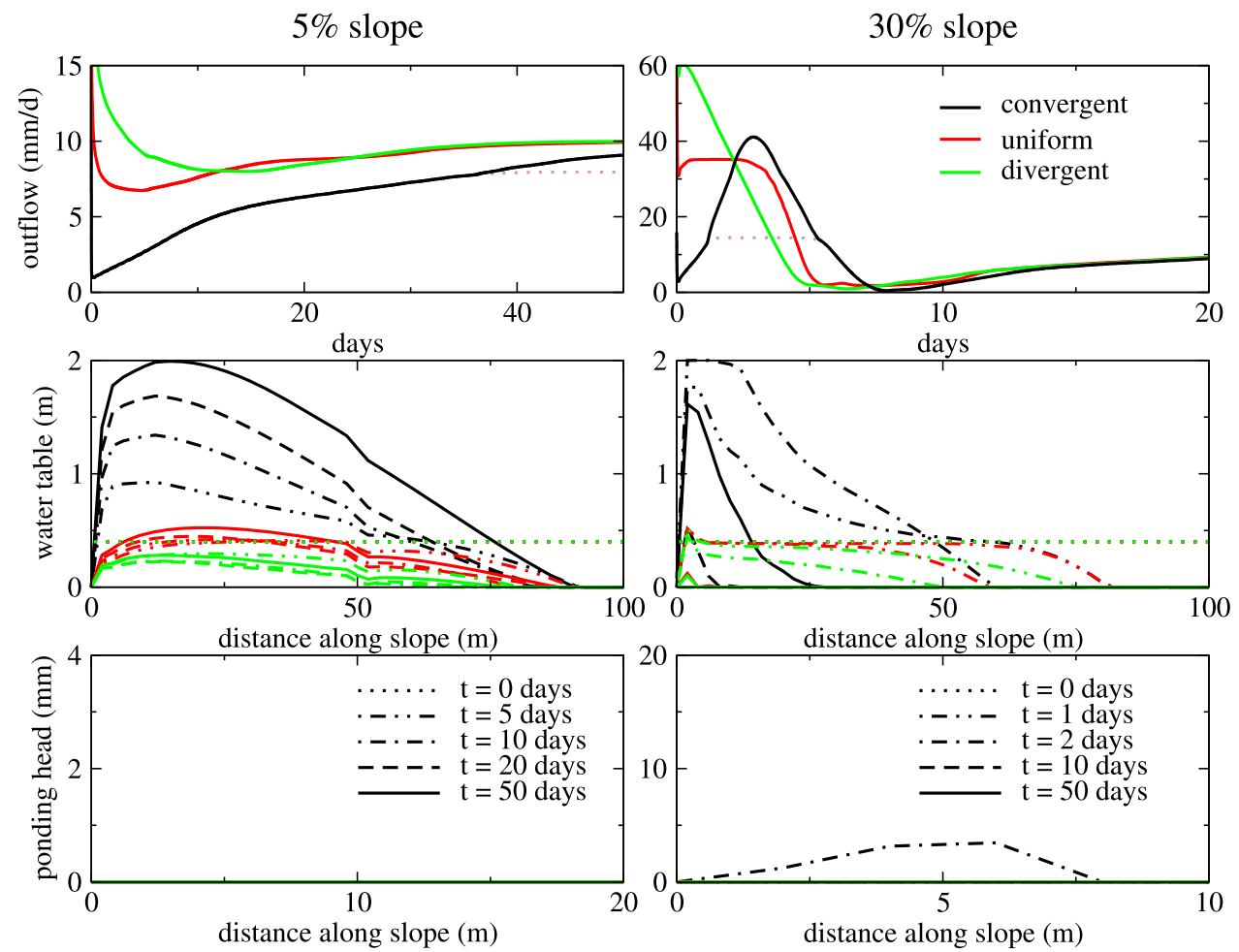

Figure 6. Convergent (black), uniform (red), and divergent (green) hillslope simulation results for the "Dirichlet runs" with (left) $5 \%$ and (right) $30 \%$ slopes: (top) total outflow rates at the outlet, (middle) water table levels above the bedrock along a central transect, and (bottom) ponding heads along a central transect. In Figure 6 (top) the onset and duration of overland flow contributions to outflow for the convergent slope are traced by the dotted grey lines; the volume of this overland contribution is gleaned from the difference between the black and dotted grey lines. A narrower range is used for the ponding head graphs in order to zoom in on where ponding occurs (at the downslope end of the hillslopes). In Figure 6 (middle) and 6 (bottom) the different curves correspond to the output times shown in the Figure 6 (bottom) legends. 

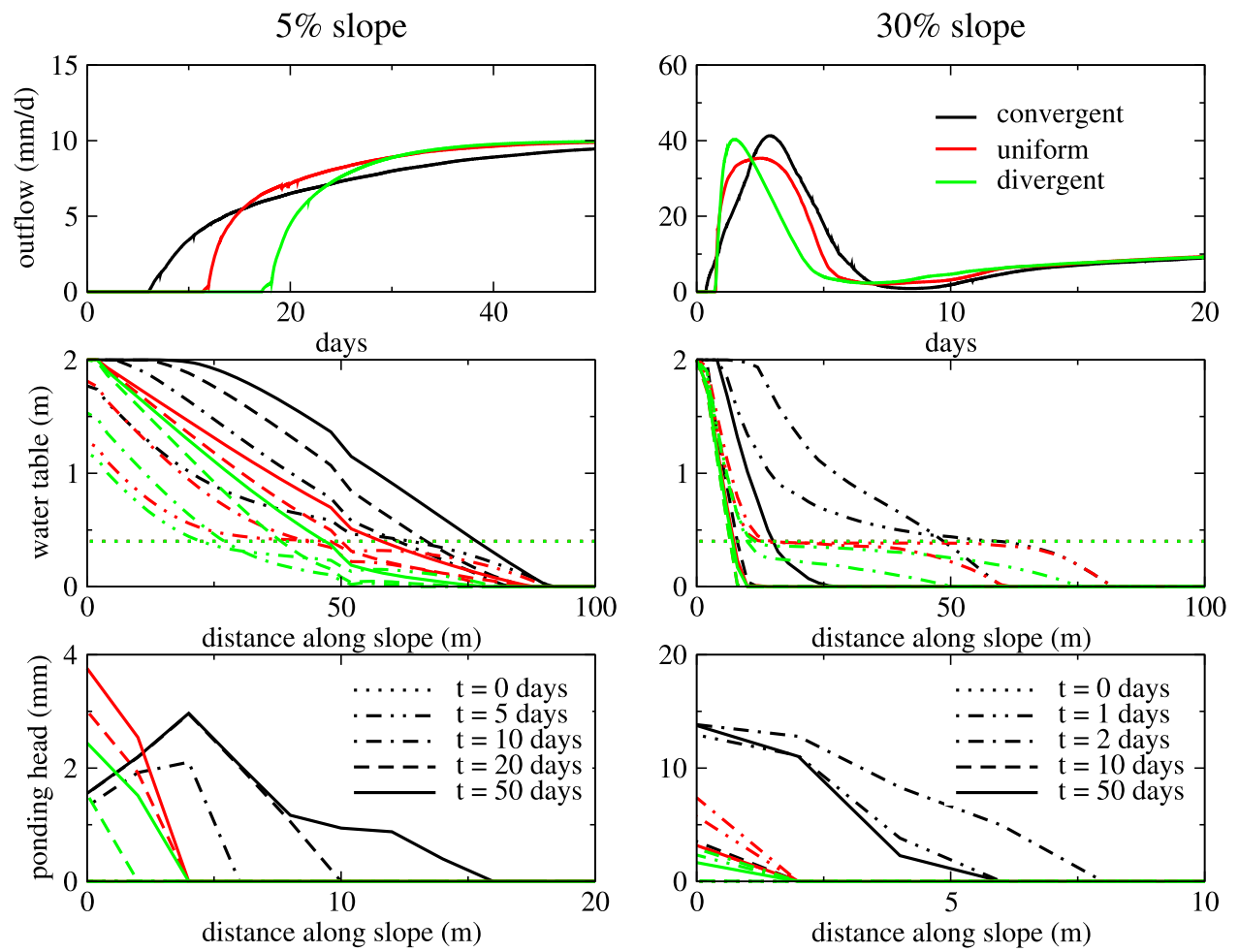

Figure 7. Convergent (black), uniform (red), and divergent (green) hillslope simulation results for the "return flow runs" with (left) $5 \%$ and (right) $30 \%$ slopes: (top) outflow rates at the outlet, (middle) water table levels above the bedrock along a central transect, (bottom) and ponding heads along a central transect. A narrower range is used for the ponding head graphs in order to zoom in on where ponding occurs (at the downslope end of the hillslopes). In these runs all the outflow is generated as overland (return) flow. In Figure 7 (middle) and 7 (bottom) panels the different curves correspond to the output times shown in the Figure 7 (bottom) legends.

is Dunnian, in contrast to the Hortonian mechanism that was dominant in the previous application). Overland flow occurs early on for the $30 \%$ slope angle, and lasts for about 4 days, whereas for the 5\% case overland flow sets in much later, as expected. Ponding, on the other hand, occurs only for the $30 \%$ convergent case, for which the surface runoff contribution is more significant. For the other two hillslopes, no surface runoff is observed at either slope angle. The outgoing fluxes are extremely high very early in these simulations, due to the discontinuity between the initial and boundary conditions, which causes the water table at the outlet to drop suddenly to zero from an initial positive height.

[54] A change in boundary conditions to the return flow configuration causes dramatic changes in early time and nearoutlet hillslope response (Figure 7) compared to the Dirichlet case. Overland flow is now generated for all hillslopes and slope angles, as water is forced to exfiltrate because of the noflow boundary condition at the outlet face. As a result, significant ponding also occurs at the surface nodes close to the outlet for all 6 runs shown in Figure 7. The ponding heads attained are highest for the convergent slopes and lowest for the divergent ones, as expected. Unlike the Dirichlet configuration, the solution adapts more gradually from initial conditions to the imposed boundary conditions, and the resulting discharge fluxes at the outlet are smoother at early time.

[55] In general, for both configurations of boundary conditions, the divergent hillslope reaches steady state first, followed by the uniform hillslope and, last, the convergent hillslope. Steady state is reached by about 20 days for all $30 \%$ slope angles and by about 40 days for the $5 \%$ slope angles except the convergent ones, which by the end of the simulations (50 days) for both Dirichlet and return flow cases have not yet reached steady state. In analogy to the similarities in late-time outflow response between the Dirichlet and return flow configurations, the water table response farther upslope, away from the outlet and near the crest, is very similar for all plan shapes and slope angles in the two boundary condition cases. The kinks in the water table profiles at a distance of about $55 \mathrm{~m}$ are due to the discontinuity in the Brooks-Corey retention curve slopes.

\subsection{Brisy Catchment}

[56] The Brisy river in Belgium is a southward flowing tributary of the Ourthe river, which in turn drains into the Meuse River. Its catchment (Figure 8) encompasses an area of $4.64 \mathrm{~km}^{2}$ and is characterized by a complex morphology, with gentle slopes in the north and steeper slopes in the south, toward the outlet. The soil is $3 \mathrm{~m}$ thick and has been discretized as reported in Table 1. Zero flow was imposed on all the lateral boundaries as well as on the bottom layer of the watershed. The model was initialized by running a 10 day drainage and evaporation simulation starting from fully saturated hydrostatic conditions in the soil and with a constant evaporation rate of $0.00025 \mathrm{~m} / \mathrm{h}(6 \mathrm{~mm} / \mathrm{d})$. Because of 


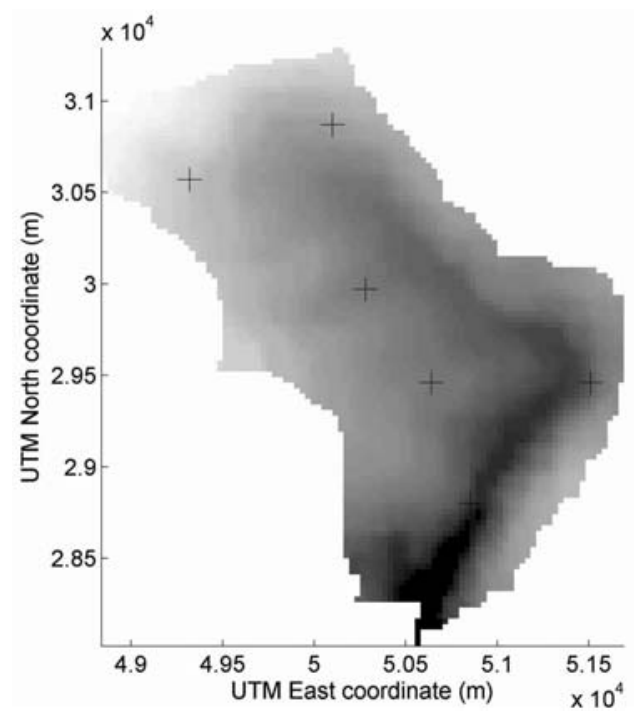

Elevation ( $m$ asl)

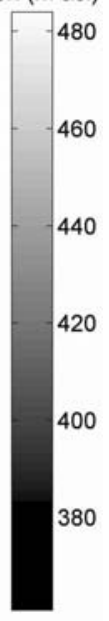

Figure 8. Shaded DEM $\left(30 \times 30 \mathrm{~m}^{2}\right)$ of the Brisy catchment, Belgium, along with the six observation points of pressure head (cross marks) for the data assimilation experiments.

the relatively low conductivity of the Brisy soils the catchment was still quite wet at the end of this initialization.

[57] A 30 day simulation was run, with atmospheric forcing specified as a step function rainfall input of $30 \mathrm{~mm} / \mathrm{h}$ for $120 \mathrm{~h}$ followed by a $12 \mathrm{~h}$ period during which the rainfall rate fell linearly to zero, another $12 \mathrm{~h}$ period of zero rainfall, a $216 \mathrm{~h}$ period during which the evaporation rate increased linearly to $0.16 \mathrm{~mm} / \mathrm{h}(3.84 \mathrm{~mm} / \mathrm{d})$, and finally a $360 \mathrm{~h}$ period with a constant evaporation rate of $0.16 \mathrm{~mm} / \mathrm{h}$. This simu- lation with an exceedingly high rainfall rate is intended to highlight the interactions between surface and subsurface flow when the catchment surface becomes very saturated or ponded, and some of the numerical manifestations of these interactions.

[58] Figure 9 presents the results of the simulation. The catchment saturates very quickly as a result of the applied rainfall and wet antecedent conditions. The actual infiltration rate consequently drops quickly to zero (Figure 9a) and the surface is completely saturated after a few hours, with actual ponding (i.e., greater than the ponding head threshold, set at $1 \mathrm{~cm}$ ) occurring over $80 \%-100 \%$ of the surface as the rainfall event progresses (Figure 9c). The rainfall rate exceeds the saturated conductivity of the topmost soil layers for the first 5 days of the simulation, so that after a very brief period needed to saturate the surface layer, infiltration excess (Horton) runoff occurs over part of the catchment. The ponding process is however dominated by saturation excess (Dunne) runoff due to the wet antecedent conditions (Figure 9c). At its peak Hortonian runoff accounts for just under $10 \%$ of the saturated area of the catchment, and its signal is lost by the second hour as the entire soil profile becomes saturated (Figure 9d). This behavior is similar to results obtained in hillslope simulations by Smith and Hebbert [1983]. Following the intense rainfall period, the atmospheric flux drops linearly to zero for $12 \mathrm{~h}$ and remains zero for another $12 \mathrm{~h}$, so that from $120 \mathrm{~h}$ the degree of ponding and saturation starts to decrease (Figure 9c), and as a consequence there is an increase in return flow exfiltration, shown as negative land surface fluxes in Figure 9b. As evaporation sets in from day 6 , this component of exfiltration gradually dominates over the return flow component, so that the exfiltration flux decreases (in absolute value) to the potential evaporation rate (Figure $9 \mathrm{~b}$ ). The saturated and ponded
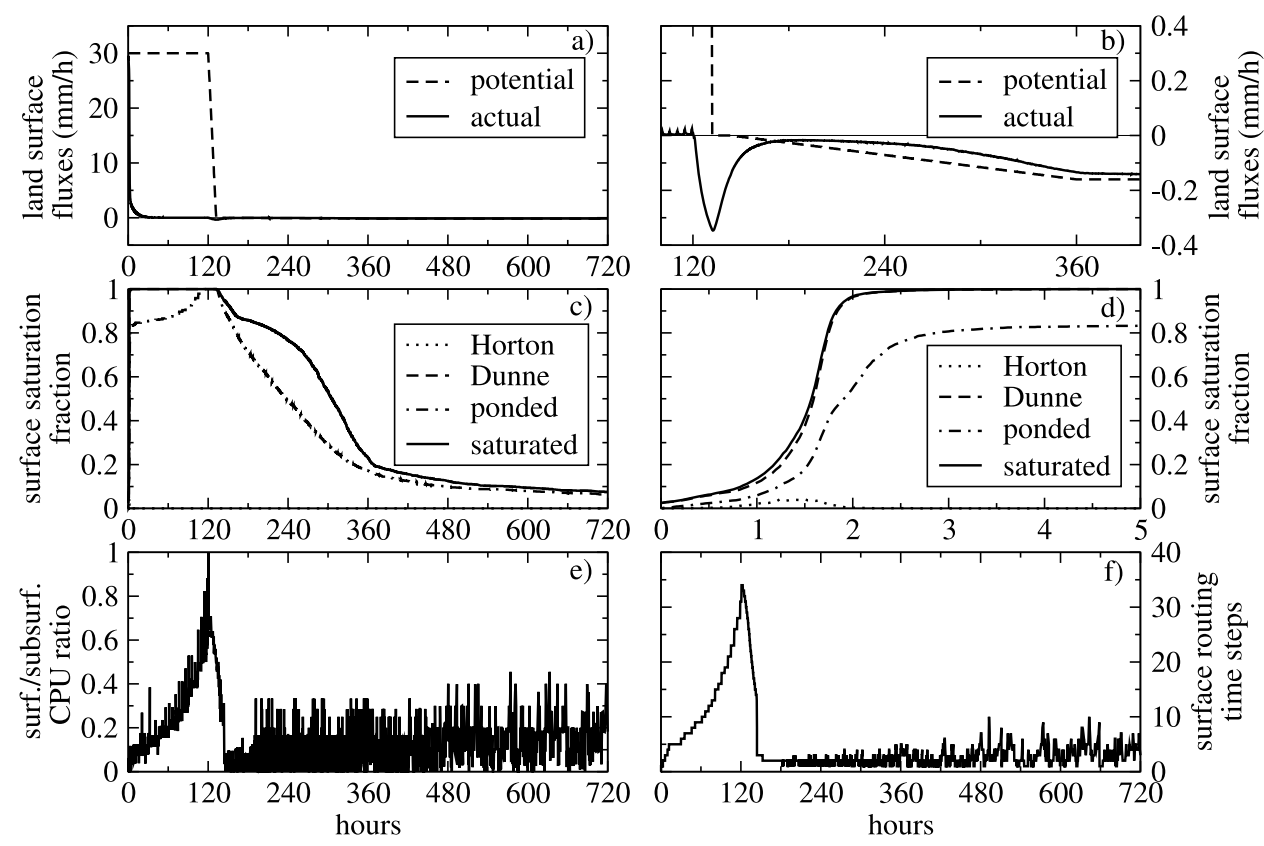

Figure 9. ( $\mathrm{a}$ and $\mathrm{b}$ ) Potential (atmospheric) and actual (model-computed) land surface fluxes, (c and d) surface saturation and ponding fractions, and (e and f) numerical behavior of the surface and subsurface modules for the 30 day Brisy simulation. Figures $9 \mathrm{~b}$ and $9 \mathrm{~d}$ provide zooms of Figures $9 \mathrm{a}$ and $9 \mathrm{c}$, respectively. 


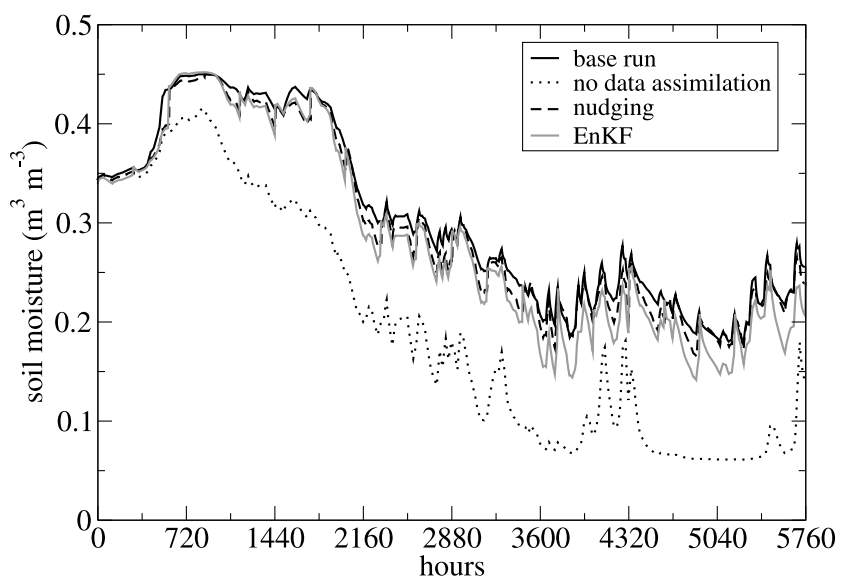

Figure 10. Time evolution of surface soil moisture as computed at one of the observation points for the base run, the nudging and EnKF assimilation runs, and the run without data assimilation for the 240 day Brisy simulation.

fractions of the catchment surface continue to decrease as evaporation proceeds, but remain nonzero through the entire simulation, as seen in Figure 9c, due to the catchment's lowconductivity soils and topography-driven redistribution of water (surface routing and subsurface return flow). This persistence accounts for a surface-subsurface interaction similar to what was observed for the small catchment with lake application. In Figure $9 \mathrm{~b}$ it is observed that during the evaporation period the actual flux across the land surface is slightly smaller (in absolute terms) than the potential flux. Given the wet conditions of the catchment after the rainfall event and its poorly drained soils, the atmospheric demand for water is satisfied during the entire evaporation period. What accounts for the actual land surface flux being smaller (in absolute value) than the potential evaporative flux is that there are surface cells that are still infiltrating even as evaporation proceeds. For these cells the evaporative demand is satisfied by the water ponded on the surface rather than by subsurface water, and the ponded water gets partitioned between evaporation and infiltration. Some aspects of the numerical behavior of the coupled model are shown in the bottom row graphs of Figure 9. During peak saturation and ponding it is observed (Figure 9e) that the surface routing module, which is explicit and 1-D, requires as much $\mathrm{CPU}$ as the nonlinear 3-D subsurface solver (see also Table 1). The reason for this is apparent in Figure 9f, where it is seen that at peak saturation the surface solver executes more than 30 time steps for each subsurface time step, which is the experimental upper limit to obtain acceptable mass balances.

[59] Using the same parameterization as for the 30 day simulation, a retrieval experiment was carried out to compare the performance of the nudging and ensemble Kalman filter data assimilation methods. The base run consists of a 240 day simulation using the time series of measured atmospheric fluxes reported by Hurkmans et al. [2006]. From the base run, "measurements" of surface pressure head were extracted every 12 days at the 6 observation points shown in Figure 8. The atmospheric boundary conditions were then biased by halving rainfall and increasing evaporation by $50 \%$ with respect to the base run data. These drier boundary conditions were then used to drive two simulations, with nudging and
EnKF, that made use of the "measured" pressure head data, and one simulation without data assimilation. The pressure head observations were assumed error-free for the two assimilation runs. Figure 10 shows the time evolution of surface soil moisture as computed at one of the observation points for the base run and the three runs with biased atmospheric boundary conditions. As expected, without data assimilation the simulation produces much drier results compared to the base run. For the data assimilation runs, on the other hand, the tendency to drying gets corrected by the 12 day observation data, with the result that these runs deviate much less from the base case solution. Newtonian nudging is able to track the base run a bit more closely than EnKF at the observation point because its time weighting function (an exponential relationship was used for this run) projects the update forward in time more directly. In terms of overall performance, however (i.e., for the entire system state), it is observed in Figure 11 that EnKF produces results far superior to nudging. This graph shows the time evolution of the pressure head root mean square error, relative to the base run and computed over all nodes of the 3-D subsurface grid, for the three runs with biased atmospheric boundary conditions. The ensemble Kalman filter is able to update nodes that are far away from the observation points if, based on the automatically computed covariance matrix, the dynamics of the state variable at these nodes is sufficiently highly correlated with the measurements. Nudging, on the other hand, relies on the characteristics of the weighting functions to propagate the measurements in space (and time), so any correlation structure needs to be explicitly built into these functions. For this run the influence range of the space weighting functions (Gaussian correlation relationships with a radius of influence of $500 \mathrm{~m}$ horizontally and $0.5 \mathrm{~m}$ vertically) was insufficient to cover the entire catchment based on only 6 observation points.

\subsection{Ged Deeble-Kalqoray Catchment}

[60] The Ged Deeble-Kalqoray catchment is located in northern Somalia, near the border with Ethiopia. In order to improve drinking water supply and distribution systems for the nearby city of Hargeisa, a hydrogeological characterization of the catchment was conducted in 2005 . The catchment encompasses an area of $356 \mathrm{~km}^{2}$ and features steeper slopes

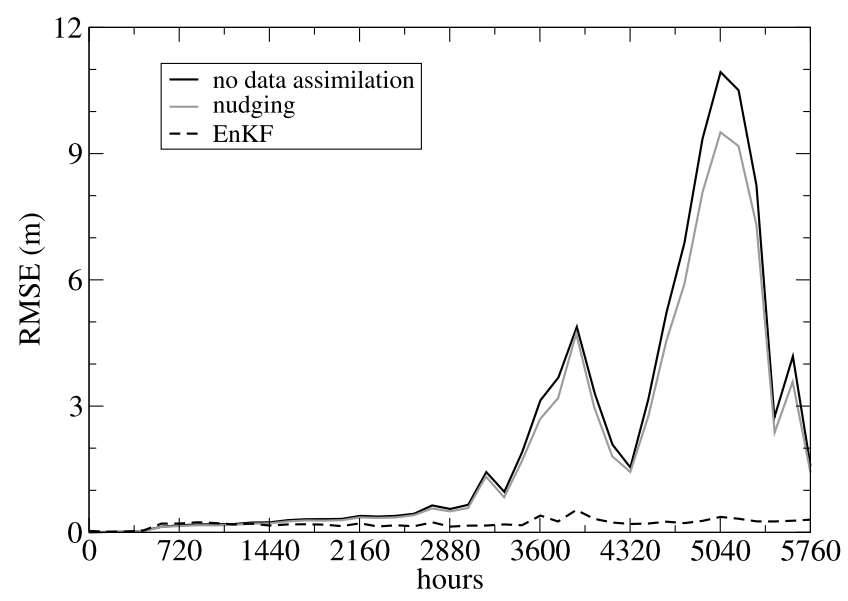

Figure 11. Time evolution of the root mean square error (RMSE) computed on the pressure heads over the entire 3-D subsurface grid for the 240 day Brisy simulation. 

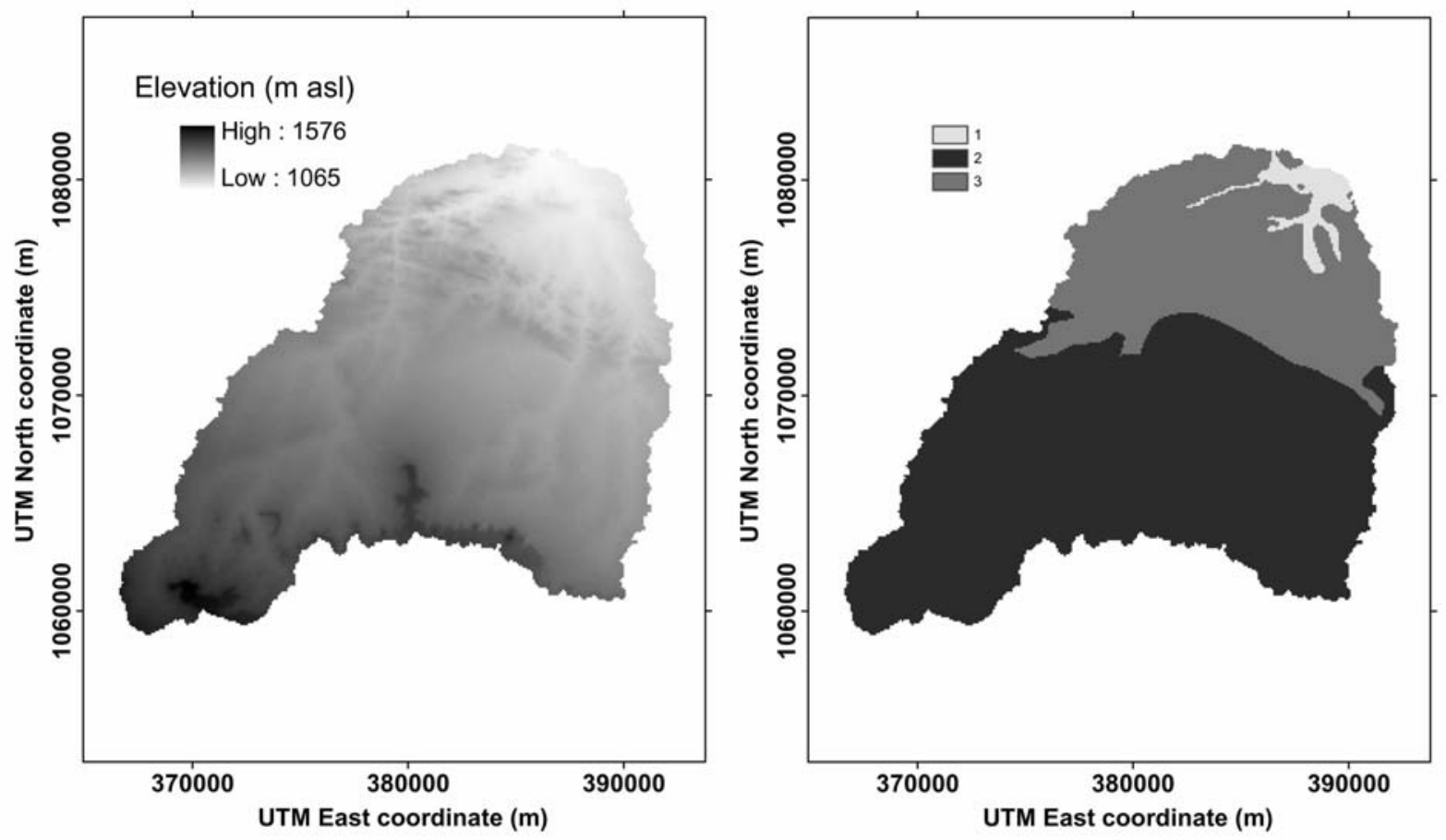

Figure 12. (left) Shaded DEM $\left(91.74 \times 91.74 \mathrm{~m}^{2}\right)$ of the Ged Deeble-Kalqoray catchment, Somalia. (right) Main geological units of the catchment, represented as zones 1 (alluvial sandy deposits), 2 (sandstone formation), and 3 (fractured metamorphic rock formation) in the model.

in the south and shallow slopes in the north, toward the outlet (Figure 12). The catchment was subdivided into three zones representing the main geological units (Figure 12): alluvial sandy deposits corresponding to the main aquifer (zone 1); a sandstone formation (zone 2); and fractured metamorphic rock outcrops (zone 3 ). The main aquifer reaches a thickness of about $200 \mathrm{~m}$ while the sandstone and rock units are progressively thinner; the discretized thickness was thus made variable, from $199 \mathrm{~m}$ in the north to $30 \mathrm{~m}$ in the south. To account for the decreasing fracturing of the metamorphic rock formation with depth, the first 10 layers of zone 3 were assigned a saturated hydraulic conductivity of $10^{-6} \mathrm{~m} / \mathrm{s}$ while the bottom 10 layers have a $K_{s}$ of $10^{-7} \mathrm{~m} / \mathrm{s}$. These and other parameters in the discretization of the Ged Deeble-Kalqoray catchment are summarized in Table 1.

[61] The aquifer system of the Ged Deeble-Kalqoray basin is recharged by infrequent rainfall events. During intense storms the lower permeability and steeper topography in the southern part of the catchment give rise to significant Horton runoff that feeds ephemeral channels or "wadi". Interstorm evaporative demand is very high in this arid region. During prolonged dry periods the soil will limit atmospheric water loss so that actual evaporation will be much less than the potential rate. These different features of the hydrologic response of the Ged Deeble-Kalqoray catchment were examined in a 6 month simulation based on precipitation data from a pluviometer in the southern portion of the catchment and potential evaporation estimates for the city of Hargeisa [Oduori et al., 2007]. In the absence of any data on the moisture deficit limits for the Ged Deeble-Kalqoray soils, an air-dry pressure head value $\left(\psi_{\min }\right)$ of $-10 \mathrm{~m}$ was used in this exploratory simulation to demarcate the switch from stage-one (atmospherecontrolled) to stage-two (soil-limited) evaporation.
[62] Figure 13 shows the atmospheric forcing and resulting outlet hydrograph for the 6 month simulation. The intense storm around day 20 generates a flash flood with peak outlet discharge of around $250 \mathrm{~m}^{3} / \mathrm{d}$. Two or three other rain events during the simulation period produce very minor overland and streamflow, while for the rest of the simulation, which includes some precipitation but mostly evaporation, the stream channels remain dry. The inset graph in Figure 13 shows that overland flow during the intense event, originating in the southern reaches of the basin, is dissipated in about 5 days as it reaches the outlet. The thicker and more permeable alluvial deposits in the northern part of the catchment around the outlet enable some of this water to

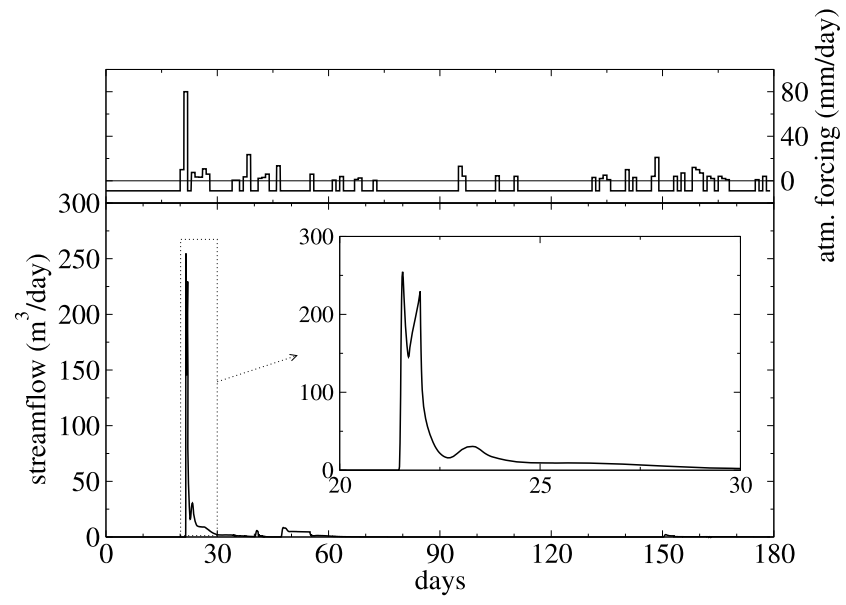

Figure 13. Atmospheric forcing and flow discharge at the catchment outlet for the Ged Deeble-Kalqoray simulation. 


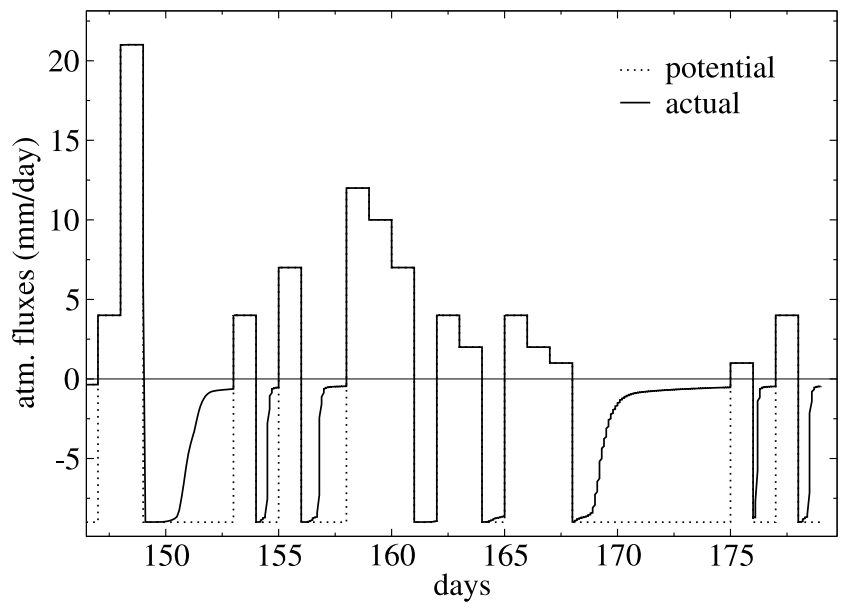

Figure 14. Comparison of potential (atmospheric) and actual (model-computed) land surface fluxes for the period from day 145 to day 179 of the Ged Deeble-Kalqoray simulation.

reinfiltrate, recharging the sandy aquifer. Figure 14 focuses on a 35 day period during the simulation and shows how, when the surface becomes too dry $\left(\psi<\psi_{\min }\right)$, boundary condition switching results in a decreasing rate of actual evaporation even as the potential rate remains high. When the potential rate decreases sufficiently, or when there is a rainfall event, the boundary condition can switch back to a Neumann type, as occurs around day 155 of the simulation.

\subsection{Chernobyl Exclusion Zone}

[63] The catchment for this application is located within the Chernobyl Exclusion Zone (CEZ), Ukraine, where interactions between surface and subsurface water played a paramount role in radionuclide contamination dynamics subsequent to the nuclear reactor accident that occurred on 26 April 1986 at the Chernobyl Nuclear Power Plant. The CEZ is characterized by a dense network of small topographic depressions that act as zones of surface flow convergence and fast vertical migration, and could therefore abet the percolation of radionuclides such as ${ }^{137} \mathrm{Cs}$ and ${ }^{90} \mathrm{Sr}$ into groundwater [Bixio et al., 2002]. These depressions are of round or elongated shape ("dishes" and "combs", respectively), range in size between 50 and $150 \mathrm{~m}$ in diameter and 0.5 and $2 \mathrm{~m}$ in depth, and have been estimated to capture more than $60 \%$ of total surface runoff. The catchment area delineated within the CEZ is shown in Figure 15, together with the 583 dishes and combs identified within this basin from satellite imagery [Bixio et al., 2002].

[64] The catchment has a surface area of $111.5 \mathrm{~km}^{2}$ and an elevation range of 98 to $152 \mathrm{~m}$ asl. The thickness of the soil and Quaternary aquifer domain considered in the simulation is $27 \mathrm{~m}$. The lateral boundaries of the catchment and the base of the aquifer were considered impermeable (the Quaternary aquifer is underlain by a low-permeability Kiev marl formation). Geological cores were used to assign saturated hydraulic conductivity values to the 8 layers in the vertical discretization. These and other parameter values are summarized in Table 1. In addition to vertical heterogeneity, a higher $K_{s}$ value, $4 \times 10^{-5} \mathrm{~m} / \mathrm{s}$, was assigned to the topmost 3 layers (3.24 m total) of the dishes and combs, compared to $4 \times$ $10^{-6} \mathrm{~m} / \mathrm{s}$ for the surrounding soil. Precipitation was derived

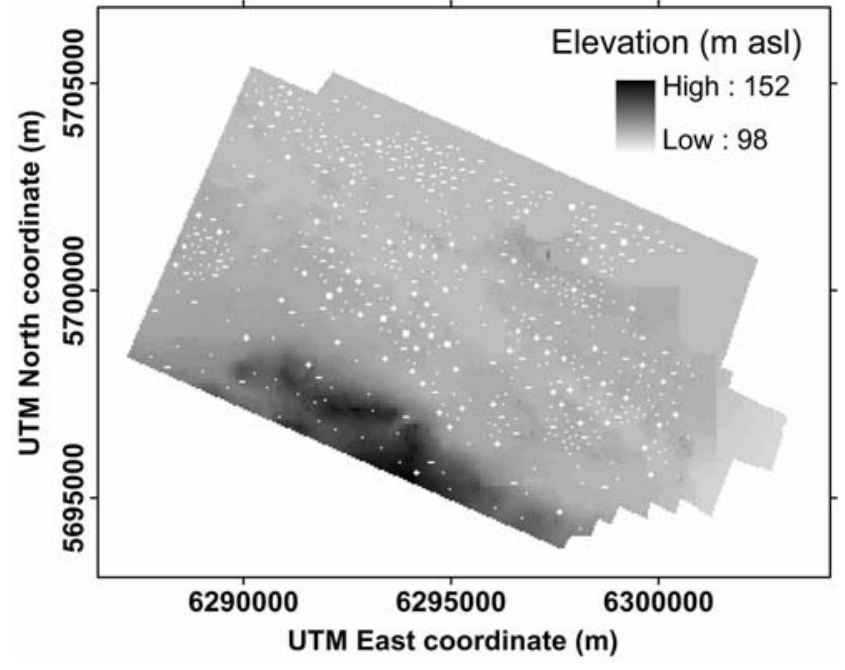

Figure 15. Shaded DEM $\left(50 \times 50 \mathrm{~m}^{2}\right)$ of the catchment area within the Chernobyl Exclusion Zone (CEZ), along with 583 topographic depressions (dishes and combs) shown as white marks.

from observed rain data for the year 1997, while average daily potential evaporation rates were calculated by the Thornthwaite formula [Chow, 1964] using observed temperature data. A 4 month base simulation (CEZ1) for the period 1 May to 28 August 1997 was performed, using as initial conditions the pressure head distribution at 1 May 1997 from the simulation reported by Bixio et al. [2002]. To better highlight the effect of the depressions as paths of preferential infiltration, two additional simulations were performed: in the first (CEZ2) dishes and combs have the same $K_{s}$ value as the surrounding soil, while in the second (CEZ3) the depressions are neglected, i.e., a depitting procedure is applied to the basin before running the simulation.

[65] Figure 16 compares the cumulative volumes of net infiltration and overland flow for the three scenarios.

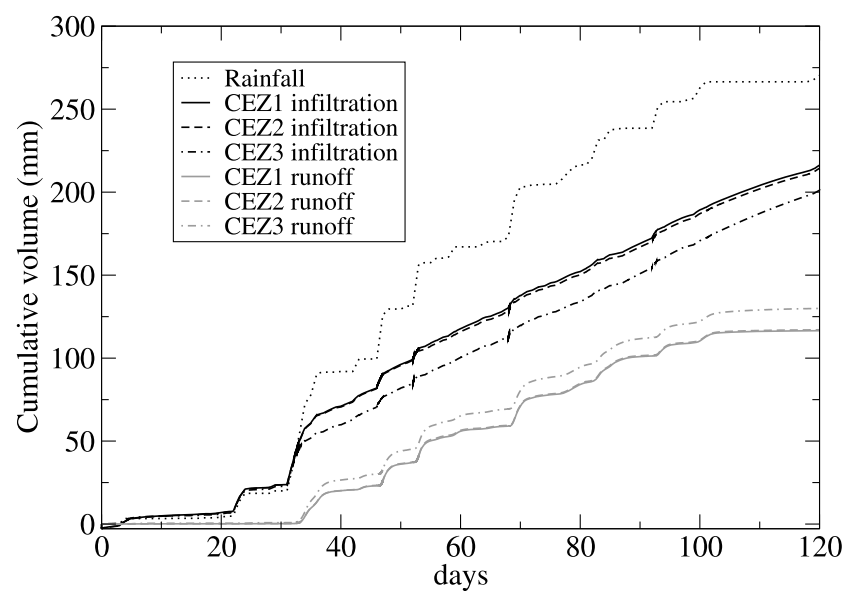

Figure 16. Comparison of cumulative volumes of infiltration and overland runoff for the three CEZ runs (CEZ1, higher $K_{s}$ for the dishes and combs; CEZ2, dishes and combs with same $K_{s}$ as the surrounding soil; CEZ3, topographic depressions depitted). Also shown is the cumulative volume of rainfall for the 4 month simulation. 


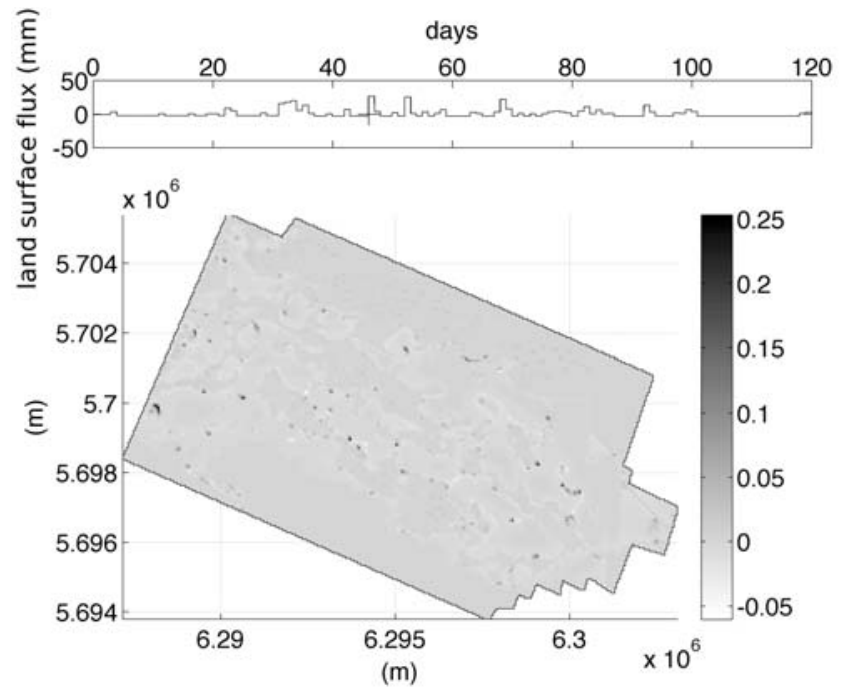

Figure 17. Difference in recharge, in $\mathrm{m}^{3} / \mathrm{d}$, at time 46 days between scenarios CEZ1 and CEZ3.

Infiltration is significant in all cases, accounting for $74 \%-$ $80 \%$ of the total rainfall by the end of the simulation, with CEZ1 and CEZ2 at the high end of this range. Conversely, CEZ3 produces the highest volume of overland runoff, due to the absence of depression storage capacity. The similarity in response between runs CEZ1 and CEZ2 suggests that the presence and morphology of the depressions has a bigger impact on hydrological response than the hydraulic conductivity of the soils in these pits, at least for the range of $K_{s}$ values investigated here. Note that for all cases the sum of infiltration and runoff is larger than the total rainfall volume, illustrating the importance of return flow even for this comparatively flat study area. Indeed return flow accounts for almost $70 \%$ of overland flow for scenario CEZ1 and more than $60 \%$ for scenario CEZ3. Figure 17 shows the difference in computed recharge, i.e., the flux of water across the water table, between scenarios CEZ1 and CEZ3 at time $46 \mathrm{~d}$. The pattern of preferential infiltration represented by the dishes and combs is well delineated by the higher recharge produced by CEZ1. Scenario CEZ3 has higher recharge only at very few points located within the river network, and this is consistent with the higher overland runoff for this run, which gets routed along the channels.

\subsection{Larch Creek Catchment}

[66] The Larch Creek Catchment (LCC) is a small (3.4 ha) headwater of the Vauz River basin $\left(1.9 \mathrm{~km}^{2}\right)$ located in the eastern Italian Alps, more specifically in the Veneto region, between the provinces of Belluno, Trento and Bolzano. Elevations in the Vauz River basin range from 1835 to $3152 \mathrm{~m}$ above sea level (asl). The area has a typical alpine climate with a mean annual precipitation of about $1220 \mathrm{~mm}$, $49 \%$ of which falls as snow. The average monthly temperature varies from $-5.7^{\circ} \mathrm{C}$ in January to $14.1^{\circ} \mathrm{C}$ in July. In the lower parts of the basin the snow cover period typically lasts from November to April. Runoff is usually dominated by snowmelt in May and June but summer and early autumn floods represent an important contribution to the flow regime [Penna et al., 2009].

[67] The LCC is located in the southwestern part of the Vauz River basin and contributes to the right-bank side of the
Vauz River basin main stem. Elevations in the LCC range from 1970 to $2120 \mathrm{~m}$ asl. Soils can be classified as Cambisol [Food and Agriculture Organization of the United Nations, 1992], characterized by clay or silty-clay loam layers underlying a deep organic matter portion. The catchment is almost unaffected by human activity (neither roads nor inhabited areas are present) and it is densely vegetated by alpine grassland, scattered shrubs and conifers. The upper part of the catchment presents the highest inclination angles (up to $48^{\circ}$ ) while the central part is characterized by gentle slopes which tend to decrease to an almost flat area, closed to the stream.

[68] The soils in the lower part of the Vauz River basin are relatively homogeneous and thus we did not consider any heterogeneity in the domain. The parameters were assigned on the basis of the characterization reported by Penna et al. [2009] and are shown in Table 1. The relatively high saturated conductivity value may reflect rapid pipe flow trough preferential paths. Rainfall and stream water level are measured by a tipping bucket rain gage and a pressure transmitter installed by a V notch sharp-crested weir, respectively, at 5 min temporal resolution. Volumetric soil moisture at $0-$ $30 \mathrm{~cm}$ depth is sampled automatically at $1 \mathrm{~h}$ time step by means of a water content reflectometer, equipped with 4 probes placed in different locations on the hillslope. Water table levels within the catchment are recorded every $5 \mathrm{~min}$ by a net of 12 capacitance rods inserted in PVC piezometric wells (Figure 18).

[69] To test the capabilities of the CATHY model to reproduce the catchment dynamics as observed in the field, we simulated a 20 day period between 17 August 2007 and 5 September 2007, including a relatively intense rainfall event followed by evaporation and minor rainfall events. The atmospheric boundary conditions consisted of rainfall as measured by the rain gage and evaporation estimated by means of the Hargreaves-Samani formula [Hargreaves and Samani, 1982] on the basis of temperature data provided by ARPAV (Environmental Protection Agency of the Veneto Region). No-flow conditions were assigned to the base of the soil domain as well as to all the lateral boundaries. The initial conditions were generated running a spin-up period of 60 days prior to the simulation, using measured rainfall rates and estimated evaporation fluxes. Our numerical experiments showed that, owing to the LCC topography and soil properties, spin-up periods of such a duration are sufficient to obtain a state that is physically consistent and essentially unaffected by the conditions assigned at the beginning of the spin-up. The pressure head and surface discharge distributions at the end of the spin-up are then used as the initial conditions for the considered simulation.

[70] The results of the simulation are shown in Figure 19, which reports the comparison between simulated and measured streamflow at the outlet, average soil moisture at the four water content probes installed and at the corresponding four nodes of the grid, and water table at the piezometer located in the riparian zone (L3 in Figure 18), together with the measured atmospheric forcing imposed at the land surface. The streamflow at the outlet simulated by the model agrees well with the measurements as regards the peak timing and base flow, but exhibits a faster than observed recession and a slight underestimation of the first two discharge peaks. As regards the match with the soil moisture, the dynamics is 

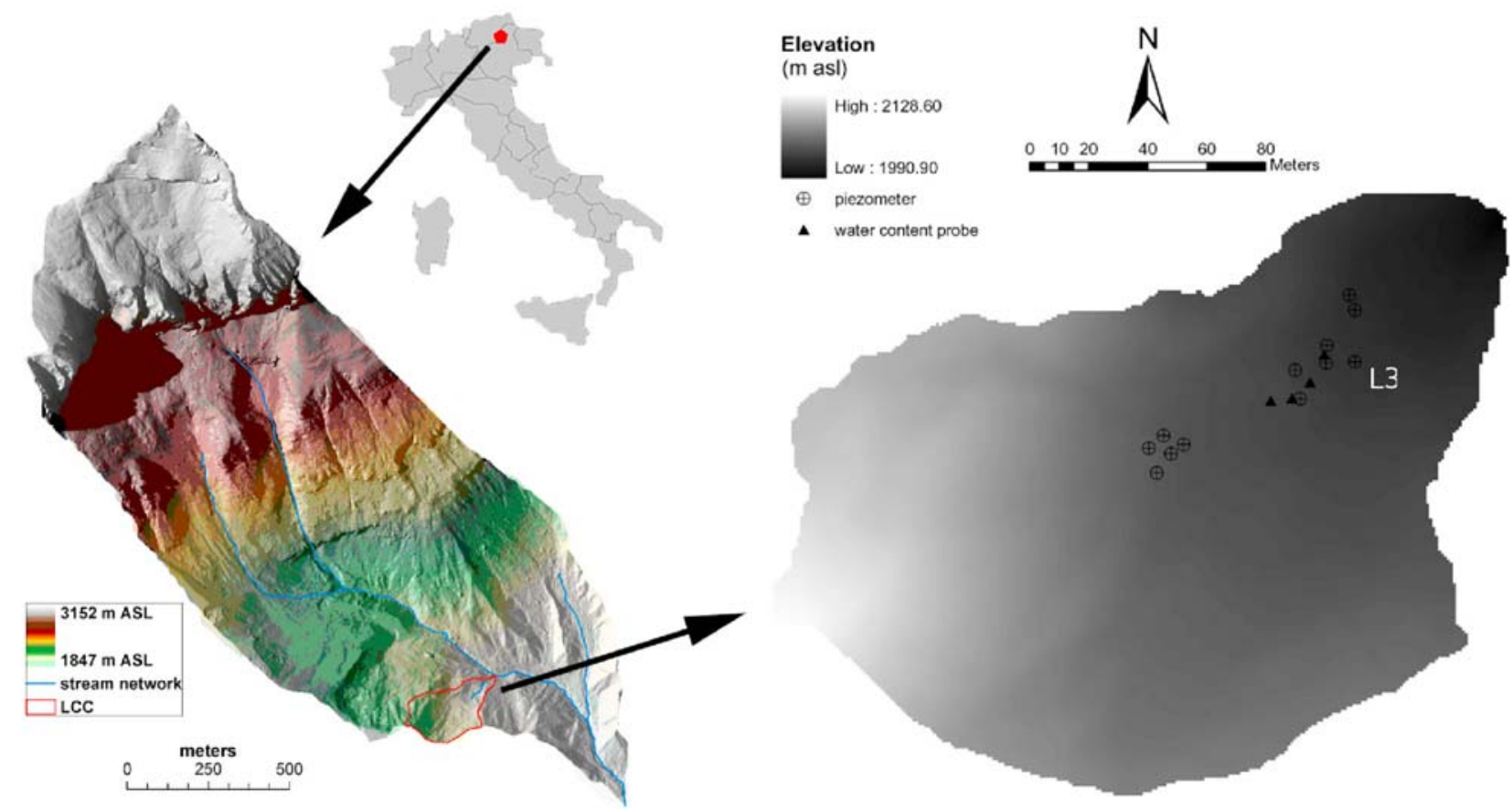

Figure 18. Map of the Larch Creek Catchment and its location within the Vauz River basin. The installed instrumentation is also shown.

fairly well captured by the model, even though the computed water content values are slightly overestimated and the peaks are a little late compared to the observations. The dynamics of the catchment response is well reproduced also for the water table, even though the model prediction exhibits greater fluctuations with respect to data. Note that the sharp peaks of the simulated water table shown in Figure 13 are due to the low time-resolution of the curve (one output point every 6 days). Also, due to the DEM-constrained grid, there are no nodes of the mesh corresponding to the L3 piezometer, thus we chose to display the average of the water table computed at the four nodes closest to the instrument location. In general, the response of the catchment, as simulated by the model with the set of parameters given by field observations and literature, tends to be sharper than observed as regards both streamflow and subsurface state.

[71] Figure 20 shows the pattern of surface saturation at two different times of the simulation: at $t=114 \mathrm{~h}$, right after the main rainfall event, and at $t=426 \mathrm{~h}$, after a few days of evaporation. The only surface runoff generation mechanism is saturation from below (Dunne) with the saturated contributing area extending beyond the usual limit of the creek, which corresponds to the extension shown in Figure 20b.

[72] Overall, considering that no calibration procedure has been applied in order to fit observed data, the simulation results obtained for the LCC are satisfactory since they prove the model's ability to capture the dynamic interaction between relevant processes occurring at the catchment scale.

\subsection{Computational Effort}

[73] The CPU times required per simulation for the six applications just described range from about $40 \mathrm{~h}$ for the $\mathrm{CEZ}$ catchment, $32 \mathrm{~h}$ for Ged Deeble-Kalqoray, $1.5 \mathrm{~h}$ for the LCC, no more than an hour for the Brisy and hillslope cases, and a few seconds for the small catchment with lake. All runs were

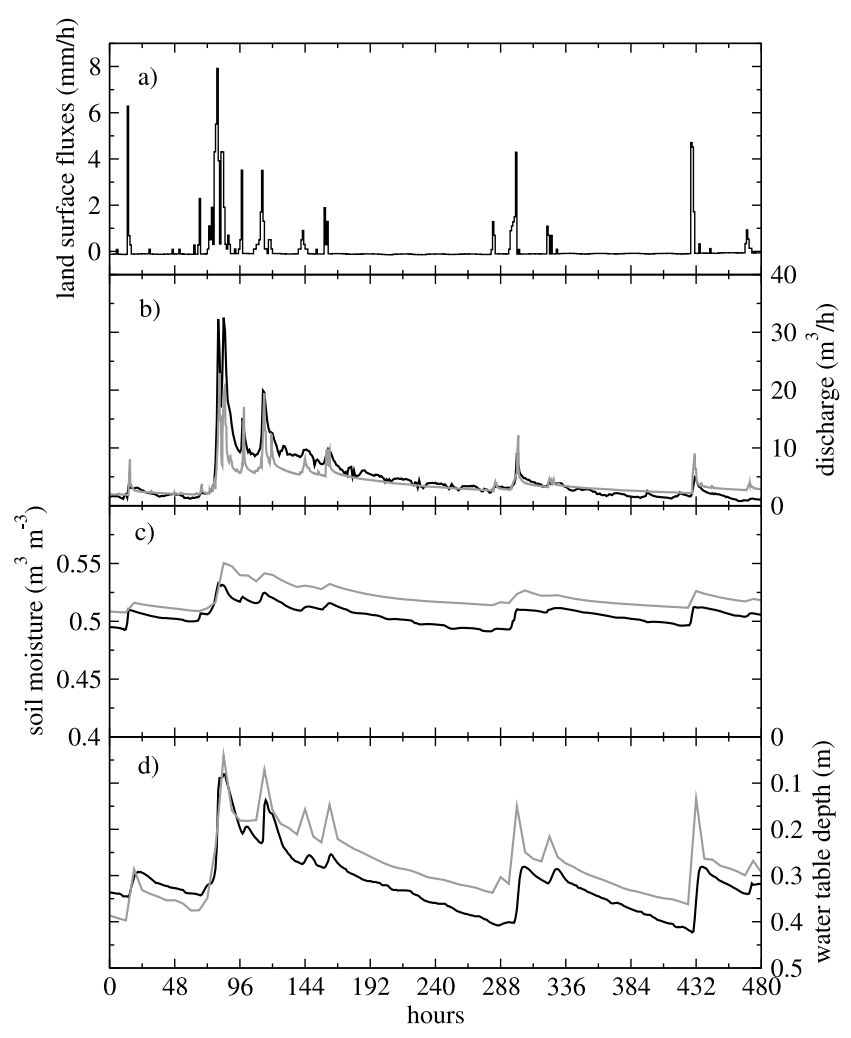

Figure 19. Larch Creek Catchment simulation: (a) land surface fluxes and (b) comparison between measured (black lines) and simulated (gray lines) streamflow at the outlet, (c) soil moisture at $0-30 \mathrm{~cm}$ depth, and (d) water table in the riparian zone. 

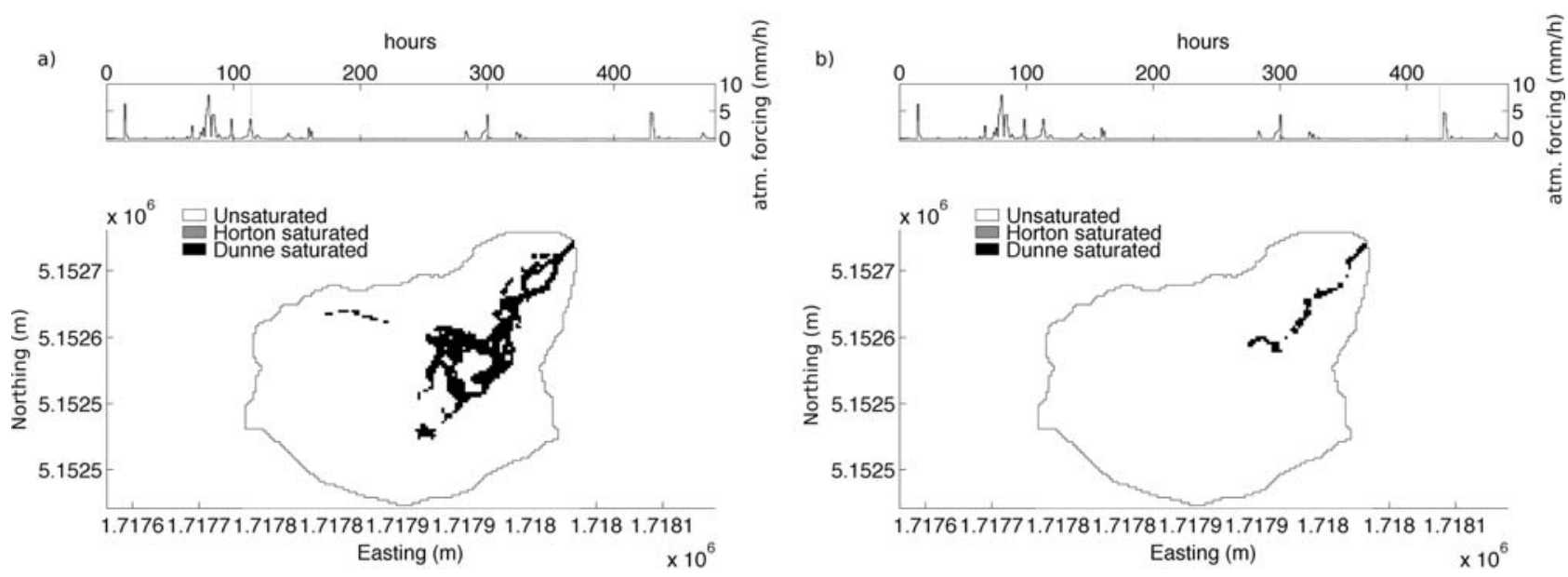

Figure 20. Larch Creek Catchment simulation: (a) pattern of surface saturation at a time of significant surface runoff generation $(t=114 \mathrm{~h})$ and $(\mathrm{b})$ at a time of the recession phase $(t=426 \mathrm{~h})$.

performed on single-processor high-end workstations and PCs. As seen from Table 1, the CEZ catchment is 30\% the size of the Ged Deeble-Kalqoray catchment and it was discretized into 8 layers compared to 20 for Ged DeebleKalqoray. The simulation period for CEZ was also shorter (4 months compared to 6). The higher CPU for the CEZ application is mainly attributable to the finer DEM used to represent the surface topography $(50 \mathrm{~m} \times 50 \mathrm{~m}$ for CEZ compared to $91.74 \mathrm{~m} \times 91.74 \mathrm{~m}$ for Ged Deeble-Kalqoray). Based on these DEMs and the respective vertical discretizations for the CEZ and Ged Deeble-Kalqoray catchments, the resulting 3-D grids contained 406,944 nodes for the former and 229,278 for the latter. As a final remark, Table 1 also reports the percentage of total CPU required for the surface and subsurface modules for each of the six applications. The most significant contribution of the surface module to the total CPU time occurs for the LCC simulation, for which the number of surface time steps ranges from a minimum of 6 to a maximum of 30 per each subsurface time step.

\section{Conclusions}

[74] A process-based coupled hydrological model of 3-D saturated/unsaturated subsurface flow and 1-D overland/ channel surface flow has been presented. Surface routing uses a path-based (rivulet flow) representation derived from topographic analysis of gridded digital elevation data, and different options are included for determining flow directions and for distinguishing between the hillslope and channel components of the surface flow domain. A threshold-based boundary condition switching procedure is used to resolve the interactions between the surface and subsurface regimes. This procedure balances potential (atmospheric) and actual (model-computed) fluxes across the land surface with changes in surface storage, determining in this way the partitioning of rainfall into infiltration and runoff, the generation of surface saturation, ponding, overland flow, and seepage, and the transition from stage-one (atmospherecontrolled) to stage-two (soil-limited) evaporation. This coupling approach allows the surface and subsurface modules to be solved sequentially, keeping computational overhead to a minimum and making possible the use of nested time stepping to account for the different dynamics and numerics between surface and subsurface flow. Additional features of the model include data assimilation schemes for updating model simulations based on spatiotemporal observation data, a simple mesh coarsening option for the subsurface grid with respect to the surface DEM, and treatment of lakes and other natural topographic depressions.

[75] Six applications over a range of scales were presented to illustrate a variety of interactions between surface and subsurface water, including Horton and Dunne runoff generation, return flow and reinfiltration processes, ponding and water table dynamics, and transitions during storm-interstorm sequences, and to examine the effects on these interactions of factors such as terrain slope and geometry, hydraulic conductivity, antecedent soil moisture conditions, and climate inputs. Challenging aspects in the simulation of surfacesubsurface interactions, alluded to in the model development and application examples include: handling the different characteristic timescales of overland, channel, soil zone, and deep groundwater flow; adequately resolving the strong nonlinearities, threshold behavior, and other complexities in hydrologic response at the land surface interface; and the need for better parameterization and direct observation of surface and subsurface parameters and state variables in a distributed manner. Each of these aspects, as well as many other issues in groundwater-surface water modeling, warrants research beyond what has been presented here. Continual advances in remote sensing, in situ measurements, numerical algorithms, and interdisciplinary research in hydrology will help meet some of these challenges.

[76] Numerous specific improvements and extensions are possible for the model described in this work. These include efficiency and accuracy measures for both the surface and subsurface modules, such as avoiding routing computations for those cells that are not ponded or are not conduits for overland flow and implementing higher order Darcy flux estimators, especially across the land surface. Different time stepping regimes could be considered for rainfall and evaporation episodes, consistent with the higher resolution often available in rainfall observations, and indeed needed in order to capture the advent of infiltration excess runoff and other processes. Local refinement of the DEM-generated surface grid would allow better representation of steep topography, 
narrow streams, and other geomorphological features without sacrificing computational efficiency; and such a mesh can be easily interfaced with the subsurface module, which in standalone mode already accepts nonuniform grids.

\section{Appendix A: Incorporation of the Hydraulic Geometry Concept Into a Diffusion Wave Model}

[77] The variation of the Gauckler-Strickler (GS) conductance coefficient $k_{S}$ at a site with upstream drainage area $A$ and flow discharge of different frequencies $Q$ can be expressed in the simple power function form

$$
k_{S}(A, Q)=r^{\prime} Q^{y^{\prime}}
$$

where $r^{\prime}$ is a scaling coefficient and $y^{\prime}$ is an exponent. The variation of $k_{S}$ between sites of upstream drainage areas $A$ with flow discharge $Q_{f}$ of given frequency $f$ can be expressed in the simple power function form

$$
k_{S}\left(A, Q_{f}\right)=r^{\prime \prime} Q_{f}^{y^{\prime \prime}}
$$

where $r^{\prime \prime}$ is a scaling coefficient and $y^{\prime \prime}$ is an exponent. From (A1) one can obtain that

$$
\frac{k_{S}(A, Q)}{k_{S}\left(A, Q_{f}\right)}=\left(\frac{Q}{Q_{f}(A)}\right)^{y^{\prime}}
$$

and from (A2) one can obtain that

$$
\frac{k_{S}\left(A, Q_{f}\right)}{k_{S}\left(A_{s}, Q_{f}\right)}=\left(\frac{Q_{f}(A)}{Q_{f}\left(A_{s}\right)}\right)^{y^{\prime \prime}}
$$

where $k_{S}\left(A_{s}, Q_{f}\right)$ denotes the value of $k_{S}$ at a site of fixed upstream drainage area $A_{s}$ and for a flow discharge $Q_{f}$ of fixed frequency $f$. Combining (A3) and (A4) yields

$$
k_{S}(A, Q)=k_{S}\left(A_{s}, Q_{f}\right)\left(\frac{Q_{f}(A)}{Q_{f}\left(A_{s}\right)}\right)^{y^{\prime \prime}}\left(\frac{Q}{Q_{f}(A)}\right)^{y^{\prime}} .
$$

Using the relationship $Q_{f}=u A^{w}$ to express the variation of $Q_{f}$ across a channel network with upstream drainage area $A$, one can obtain

$$
\frac{Q_{f}(A)}{Q_{f}\left(A_{S}\right)}=\left(\frac{A}{A_{s}}\right)^{w}
$$

The at-a-station relationship $k_{S}(A, Q)=k_{S}(A, 1) Q^{y^{\prime}}$ with $k_{S}(A, 1)$ given by (5) can be obtained combining equations (A5) and (A6) so as to eliminate $Q_{f}(A)$. A similar formulation allows one to derive the at-a-station relationship $W(A, Q)=W(A, 1) Q^{y^{\prime}}$ with $W(A, 1)$ given by (6) for watersurface width.

[78] Equation (3) is obtained on the basis of the definition of celerity, $c_{k}=d Q / d \Omega=-\left(\partial S_{f} / \partial \Omega\right) /\left(\partial S_{f} / \partial Q\right)$ [Orlandini and Rosso, 1998], and the Gauckler-Manning-Strickler expres- sion, $Q=k_{S} W^{-2 / 3} \Omega^{5 / 3} S_{f}^{1 / 2}$ [Hager, 2000], where $S_{f}$ is the friction slope and $\Omega$ is the cross-sectional flow area. If $k_{S}$ and $W$ are allowed to vary with $Q$, one can obtain that

$$
-\frac{\partial S_{f} / \partial \Omega}{\partial S_{f} / \partial Q}=\frac{5}{3} \frac{Q}{\Omega} /\left(1-\frac{Q}{k_{S}} \frac{d k_{S}}{d Q}+\frac{2 Q}{3 W} \frac{d W}{d Q}\right) .
$$

Using the relationships $k_{S}(A, Q)=k_{S}(A, 1) Q^{y^{\prime}}$, with $k_{S}(A, 1)$ given by $(5)$, and $W(A, Q)=W(A, 1) Q^{y^{\prime}}$, with $W(A, 1)$ given by (6), to express the variations of $k_{S}$ and $W$ with $Q$, respectively, yields equation (3). Equation (4) is obtained on the basis of equations $D_{h}=\cos \beta /\left(W \partial S_{f} / \partial Q\right)$ [Hayami, 1951; Orlandini and Rosso, 1998] and $Q=k_{S} W^{-2 / 3} \Omega^{5 / 3} S_{f}^{1 / 2}$. If $k_{S}$ and $W$ are allowed to vary with $Q$, one can obtain that

$$
\left(\frac{W}{\cos \beta} \frac{\partial S_{f}}{\partial Q}\right)^{-1}=\frac{Q \cos \beta}{2 W S_{f}} /\left(1-\frac{Q}{k_{S}} \frac{d k_{S}}{d Q}+\frac{2 Q}{3 W} \frac{d W}{d Q}\right) .
$$

Using the relationships $k_{S}(A, Q)=k_{S}(A, 1) Q^{y^{\prime}}$, with $k_{S}(A, 1)$ given by $(5)$, and $W(A, Q)=W(A, 1) Q^{y^{\prime}}$, with $W(A, 1)$ given by (6), to express the variations of $k_{S}$ and $W$ with $Q$, respectively, yields equation (4).

[79] Acknowledgments. The financial support of the Ouranos Consortium and the Natural Sciences and Engineering Research Council of Canada (project CRDPJ-319968-04) and of the CARIPARO foundation ("Transport phenomena in hydrological catchments: Hydrological and geophysical experiments and modelling" project) is acknowledged. Bruno Petrucci (Africa '70) and Julien Lecollinet (MED Ingegneria S.r.1.) are gratefully acknowledged for their assistance in providing data and other input for the simulation of the Ged Deeble-Kalqoray catchment. Many thanks also to Giancarlo Dalla Fontana, Marco Borga, and Daniele Penna (Dipartimento Territorio e Sistemi Agro-Forestali, University of Padova) for providing all data for the simulation of the Larch Creek Catchment. Finally, we thank the Associate Editor and three anonymous reviewers for their detailed and very helpful comments.

\section{References}

Ababou, R., and G. Trégarot (2002), Coupled modeling of partially saturated flow: Macro-porous media, interfaces, variability, in Proceedings $X I V$ International Conference on Computational Methods in Water Resources, edited by A. M. Hassanizadeh et al., pp. 49-56, Elsevier, Amsterdam, Neth.

Abrahams, A. D., G. Li, and A. J. Parsons (1996), Rill hydraulics on a semiarid hillslope, southern Arizona, Earth Surf. Processes Landforms, $21,35-47$.

Anderson, E. I. (2005), Modeling groundwater-surface water interactions using the Dupuit approximation, Adv. Water Resour., 28(4), 315-327.

Bajracharya, K., and D. A. Barry (1997), Accuracy criteria for linearised diffusion wave flood routing, J. Hydrol., 195, 200-217.

Bixio, A. C., S. Orlandini, C. Paniconi, and M. Putti (2000), Physicallybased distributed model for coupled surface runoff and subsurface flow simulation at the catchment scale, in Proceedings XIII International Conference on Computational Methods in Water Resources, edited by L. R. Bentley et al., pp. 1115-1122, Balkema, Rotterdam, Neth.

Bixio, A. C., G. Gambolati, C. Paniconi, M. Putti, V. M. Shestopalov, V. N. Bublias, A. S. Bohuslavsky, N. B. Kastelteseva, and Y. F. Rudenko (2002), Modeling groundwater-surface water interactions including effects of morphogenetic depressions in the Chernobyl exclusion zone, Environ. Geol., 42, 162-177.

Blasch, K. W., T. P. A. Ferré, J. P. Hoffmann, and J. B. Fleming (2006), Relative contributions of transient and steady state infiltration during ephemeral streamflow, Water Resour. Res., 42, W08405, doi:10.1029/ 2005WR004049.

Brooks, R. H., and A. T. Corey (1964), Hydraulic properties of porous media, Hydrol. Pap. 3, Colo. State Univ., Fort Collins.

Camporese, M., S. Ferraris, M. Putti, P. Salandin, and P. Teatini (2006a), Hydrological modeling in swelling/shrinking peat soils, Water Resour. Res., 42, W06420, doi:10.1029/2005WR004495. 
Camporese, M., C. Paniconi, M. Putti, P. Salandin, and P. Teatini (2006b), Two dimensional hydrological simulation in elastic swelling/shrinking peat soils, in Proceedings XVI International Conference on Computational Methods in Water Resources, p. 8, Tech. Univ. of Den., Copenhagen, (Available at http://proceedings.cmwr-xvi.org/materialDisplay.py? contribId $=112 \&$ sessionId $=10 \&$ materialId $=$ paper\& confId $=\mathrm{a} 051$ )

Camporese, M., C. Paniconi, M. Putti, and P. Salandin (2009a), Ensemble Kalman filter data assimilation for a process-based catchment scale model of surface and subsurface flow, Water Resour. Res., 45, W10421, doi:10.1029/2008WR007031.

Camporese, M., C. Paniconi, M. Putti, and P. Salandin (2009b), A comparison of data assimilation techniques for a coupled model of surface and subsurface flow, Vadose Zone J., 8, 837-845.

Chow, V. T. (Ed.) (1964), Handbook of Applied Hydrology, McGraw-Hill, New York.

Clark, M. P., D. E. Woods, R. A. Woods, X. Zheng, R. P. Ibbitt, A. G. Slater, J. Schmidt, and M. J. Uddstrom (2008), Hydrological data assimilation with the ensemble Kalman filter: Use of streamflow observations to update states in a distributed hydrological model, Adv. Water Resour., $31,1309-1324$.

Crow, W. T., and E. F. Wood (2003), The assimilation of remotely sensed soil brightness temperature imagery into a land surface model using ensemble Kalman filtering: A case study based on ESTAR measurements during SGP97, Adv. Water Resour., 26(2), 137-149.

Cunge, J. A. (1969), On the subject of a flood propagation computation method (Muskingum method), J. Hydraul. Res., 7(2), 205-230.

D'Haese, C. M. F., M. Putti, C. Paniconi, and N. E. C. Verhoest (2007), Assessment of adaptive and heuristic time stepping for variably saturated flow, Int. J. Numer. Methods Fluids, 53(7), 1173-1193.

Downer, C. W., and F. L. Ogden (2003), Prediction of runoff and soil moistures at the watershed scale: Effects of model complexity and parameter assignment, Water Resour. Res., 39(3), 1045, doi:10.1029/2002WR001439.

Emmett, W. W. (1978), Overland flow, in Hillslope Hydrology, edited by M. J. Kirkby, p. 145-176, John Wiley, New York.

Fan, Y., and R. L. Bras (1998), Analytical solutions to hillslope subsurface storm flow and saturation overland flow, Water Resour. Res., 34(4), $921-$ 927.

Fan, Y., L. Toran, and R. W. Schlische (2007), Groundwater flow and groundwater-stream interaction in fractured and dipping sedimentary rocks: Insights from numerical models, Water Resour. Res., 43, W01409, doi:10.1029/2006WR004864.

Food and Agriculture Organization of the United Nations (1992), Legend of the soil map of the world 1974, technical report, U. N. Educ. Sci. and Cult. Org., Paris.

Freeze, R. A. (1971), Three-dimensional, transient, saturated-unsaturated flow in a groundwater basin, Water Resour. Res., 7(2), 347-366.

Furman, A. (2008), Modeling coupled surface-subsurface flow processes: A review, Vadose Zone J., 7(2), 741-756.

Giannoni, F., G. Roth, and R. Rudari (2005), A procedure for drainage network identification from geomorphology and its application to the prediction of the hydrologic response, Adv. Water Resour., 28(6), 567581 .

Graham, D. N., and M. B. Butts (2005), Flexible, integrated watershed modelling with MIKE SHE, in Watershed Models, edited by V. P. Singh and D. K. Frevert, chap. 10, pp. 245-272, CRC Press, Boca Raton, Fla.

Gunduz, O., and M. M. Aral (2005), River networks and groundwater flow: A simultaneous solution of a coupled system, J. Hydrol., 301, 216-234.

Hager, W. H. (2000), Gauckler and the GMS formula, J. Hydraul. Eng., $127,635-638$

Hargreaves, G. H., and Z. A. Samani (1982), Estimating potential evapotranspiration, J. Irrig. Drain. Eng., 108(3), 225-230.

Harvey, J. W., and K. E. Bencala (1993), The effect of streambed topography on surface-subsurface water exchange in mountain catchments, Water Resour. Res., 29(1), 89-98.

Hayami, S. (1951), On the propagation of flood waves, Bull. Disaster Prev. Res. Inst., Kyoto Univ., 1(1), 1-16.

Hollinger, S. E., and S. A. Isard (1994), A soil moisture climatology of Illinois, J. Clim., 7, 822-833.

Howard, A. D. (1994), A detachment-limited model of drainage basin evolution, Water Resour. Res., 30(7), 2261-2285.

Hurkmans, R., C. Paniconi, and P. A. Troch (2006), Numerical assessment of a dynamical relaxation data assimilation scheme for a catchment hydrological model, Hydrol. Processes, 20, 549-563.

Huyakorn, P. S., S. D. Thomas, and B. M. Thompson (1984), Techniques for making finite elements competitive in modeling flow in variably saturated porous media, Water Resour. Res., 20(8), 1099-1115.
Huyakorn, P. S., E. P. Springer, V. Guvanasen, and T. D. Wadsworth (1986), A three-dimensional finite-element model for simulating water flow in variably saturated porous media, Water Resour. Res., 22(13), 1790-1808.

Ivanov, V. Y., E. R. Vivoni, R. L. Bras, and D. Entekhabi (2004), Catchment hydrologic response with a fully distributed triangulated irregular network model, Water Resour. Res., 40, W11102, doi:10.1029/ 2004WR003218.

Jones, J. P., E. A. Sudicky, and R. G. McLaren (2008), Application of a fully-integrated surface-subsurface flow model at the watershed-scale: A case study, Water Resour. Res., 44, W03407, doi:10.1029/2006WR005603.

Kampf, S. K., and S. J. Burges (2007), A framework for classifying and comparing distributed hillslope and catchment hydrologic models, Water Resour. Res., 43, W05423, doi:10.1029/2006WR005370.

Kollet, S. J., and R. M. Maxwell (2006), Integrated surface-groundwater flow modeling: A free-surface overland flow boundary condition in a parallel groundwater flow model, Adv. Water Resour., 29(7), 945-958.

Koussis, A. D., M. E. Smith, E. Akylas, and M. Tombrou (1998), Groundwater drainage flow in a soil layer resting on an inclined leaky bed, Water Resour. Res., 34(11), 2879-2887.

Leopold, L. B., and T. Maddock Jr. (1953), The hydraulic geometry of stream channels and some physiographic implications, Prof. Pap. 252, U.S. Geol. Surv., Washington, D.C.

Leopold, L. B., M. G. Wolman, and J. P. Miller (1964), Fluvial Processes in Geomorphology, W. H. Freeman, San Francisco, Calif.

Levine, J. B., and G. D. Salvucci (1999), Equilibrium analysis of groundwater-vadose zone interactions and the resulting spatial distribution of hydrologic fluxes across a Canadian prairie, Water Resour. Res., 35(5), $1369-1383$.

Li, R. M., V. M. Ponce, and D. B. Simons (1980), Modeling rill density, J. Irrig. Drain. Eng., 106(1), 63-67.

Mackay, D. S., and L. E. Band (1998), Extraction and representation of nested catchment areas from digital elevation models in lake-dominated topography, Water Resour. Res., 34(4), 897-901.

Margulis, S. A., D. McLaughlin, D. Entekhabi, and S. Dunne (2002), Land data assimilation and estimation of soil moisture using measurements from the Southern Great Plains 1997 Field Experiment, Water Resour. Res., 38(12), 1299, doi:10.1029/2001WR001114.

Marks, D., J. Dozier, and J. Frew (1984), Automated basin delineation from digital elevation data, Geo. Process., 2, 299-311.

Michaud, J., and S. Sorooshian (1994), Comparison of simple versus complex distributed runoff models on a midsized semiarid watershed, Water Resour. Res., 30(3), 593-605.

Milly, P. C. D., and R. T. Wetherald (2002), Macroscale water fluxes: 3. Effects of land processes on variability of monthly river discharge, Water Resour. Res., 38(11), 1235, doi:10.1029/2001WR000761.

Montgomery, D. R., and W. E. Dietrich (1988), Where do channels begin?, Nature, 336, 232-234.

Montgomery, D. R., and W. E. Dietrich (1989), Source areas, drainage density, and channel initiation, Water Resour. Res., 25(8), 1907-1918.

Montgomery, D. R., and E. Foufoula-Georgiou (1993), Channel network source representation using digital elevation models, Water Resour. Res., 29(12), 3925-3934.

Moretti, G., and S. Orlandini (2008), Automatic delineation of drainage basins from contour elevation data using skeleton construction techniques, Water Resour. Res., 44, W05403, doi:10.1029/2007WR006309.

Morita, M., and B. C. Yen (2002), Modeling of conjunctive twodimensional surface-three-dimensional subsurface flows, J. Hydraulic Eng., 128(2), 184-200.

Nachabe, M. H. (2002), Analytical expressions for transient specific yield and shallow water table drainage, Water Resour. Res., 38(10), 1193, doi:10.1029/2001WR001071.

Nikolaidis, N. P., H.-L. Hu, C. Ecsedy, and J. D. Lin (1993), Hydrologic response of freshwater watersheds to climatic variability: Model development, Water Resour. Res., 29(10), 3317-3328.

O'Callaghan, J. F., and D. M. Mark (1984), The extraction of drainage networks from digital elevation data, Comput. Vision Graphics Image Process., 28, 323-344.

Oduori, S., R. Vargas, and M. Alim (2007), Land use characterisation of a selected study area in Somaliland, Proj. Rep. L-04, U.N., Food and Agriculture Organization, Nairobi.

Orlandini, S. (2002), On the spatial variation of resistance to flow in upland channel networks, Water Resour. Res., 38(10), 1197, doi:10.1029/ 2001 WR001187.

Orlandini, S., and G. Moretti (2009a), Determination of surface flow paths from gridded elevation data, Water Resour. Res., 45, W03417, doi:10.1029/2008WR007099. 
Orlandini, S., and G. Moretti (2009b), Comment on "Global search algorithm for nondispersive flow path extraction" by Kyungrock Paik, J. Geophys. Res., 114, F04004, doi:10.1029/2008JF001193.

Orlandini, S., and R. Rosso (1996), Diffusion wave modeling of distributed catchment dynamics, J. Hydrol. Eng., 1(3), 103-113.

Orlandini, S., and R. Rosso (1998), Parameterization of stream channel geometry in the distributed modeling of catchment dynamics, Water Resour. Res., 34(8), 1971-1985.

Orlandini, S., G. Moretti, M. Franchini, B. Aldighieri, and B. Testa (2003), Path-based methods for the determination of nondispersive drainage directions in grid-based digital elevation models, Water Resour. Res., 39(6), 1144, doi:10.1029/2002WR001639.

Panday, S., and P. S. Huyakorn (2004), A fully coupled physically-based spatially-distributed model for evaluating surface/subsurface flow, $A d v$. Water Resour., 27, 361-382.

Paniconi, C., and M. Putti (1994), A comparison of Picard and Newton iteration in the numerical solution of multidimensional variably saturated flow problems, Water Resour. Res., 30(12), 3357-3374.

Paniconi, C., and E. F. Wood (1993), A detailed model for simulation of catchment scale subsurface hydrologic processes, Water Resour. Res., 29(6), $1601-1620$.

Paniconi, C., P. A. Troch, E. E. van Loon, and A. G. J. Hilberts (2003a), Hillslope-storage Boussinesq model for subsurface flow and variable source areas along complex hillslopes: 2 . Intercomparison with a threedimensional Richards equation model, Water Resour. Res., 39(11), 1317, doi:10.1029/2002WR001730.

Paniconi, C., M. Marrocu, M. Putti, and M. Verbunt (2003b), Newtonian nudging for a Richards equation-based distributed hydrological model, Adv. Water Resour., 26(2), 161-178.

Parsons, A. J., A. D. Abrahams, and J. Wainwright (1994), On determining resistance to interrill overland flow, Water Resour. Res., 30(12), 35153521 .

Penna, D., M. Borga, D. Norbiato, and G. Dalla Fontana (2009), Hillslope scale soil moisture variability in a steep alpine terrain, J. Hydrol., 364, $311-327$.

Pohll, G. M., J. J. Warwick, and S. W. Tyler (1996), Coupled surfacesubsurface hydrologic model of a nuclear subsidence crater at the Nevada test site, J. Hydrol., 186, 43-62.

Ponce, V. M. (1986), Diffusion wave modeling of catchment dynamics, J. Hydraul. Eng., 112(8), 716-727.

Qu, Y., and C. J. Duffy (2007), A semidiscrete finite volume formulation for multiprocess watershed simulation, Water Resour. Res., 43, W08419, doi:10.1029/2006WR005752.

Raudkivi, A. J. (1979), Hydrology: An Advanced Introduction to Hydrological Processes and Modelling, Pergamon, New York.

Reggiani, P., S. M. Hassanizadeh, M. Sivapalan, and W. G. Gray (1999), A unifying framework for watershed thermodynamics: Constitutive relationships, Adv. Water Resour., 23, 15-39.

Rigon, R., G. Bertoldi, and T. Over (2006), A distributed hydrological model with coupled water and energy budgets, J. Hydrometeorol., 7(3), 371-388.

Rinaldo, A., M. Marani, and R. Rigon (1991), Geomorphological dispersion, Water Resour. Res., 27(4), 513-525.

Robinson, J. S., M. Sivapalan, and J. D. Snell (1995), On the relative roles of hillslope processes, channel routing, and network geomorphology in the hydrologic response of natural catchments, Water Resour. Res., 31(12), 3089-3101.
Salvucci, G. D. (1997), Soil and moisture independent estimation of stagetwo evaporation from potential evaporation and albedo or surface temperature, Water Resour. Res., 33(1), 111-122.

Sankarasubramanian, A., R. M. Vogel, and J. F. Limbrunner (2001), Climate elasticity of streamflow in the United States, Water Resour. Res., 37(6), 1771-1781.

Seyfried, M. S., and B. P. Wilcox (1995), Scale and the nature of spatial variability: Field examples having implications for hydrologic modeling, Water Resour. Res., 31(1), 173-184.

Singh, V., and S. M. Bhallamudi (1998), Conjuctive surface-subsurface modeling of overland flow, Adv. Water Resour, 21, 567-579.

Smith, M. B., K. P. Georgakakos, and X. Liang (2004), The distributed model intercomparison project (DMIP), J. Hydrol., 298, 1-3.

Smith, R. E., and R. H. B. Hebbert (1983), Mathematical simulation of interdependent surface and subsurface hydrologic processes, Water Resour. Res., 19(4), 987-1001.

Storey, R. G., K. W. F. Howard, and D. D. Williams (2003), Factors controlling riffle-scale hyporheic exchange flows and their seasonal changes in a gaining stream: A three-dimensional groundwater flow model, Water Resour. Res., 39(2), 1034, doi:10.1029/2002WR001367.

Syriopoulou, D., and A. D. Koussis (1991), Two-dimensional modeling of advection-dominated solute transport in groundwater by the matched artificial dispersivity method, Water Resour. Res., 27(5), 865-872.

Tarboton, D. G. (1997), A new method for the determination of flow directions and contributing areas in grid digital elevation models, Water Resour. Res., 33(2), 309-319.

VanderKwaak, J. E., and K. Loague (2001), Hydrologic-response simulations for the R-5 catchment with a comprehensive physics-based model, Water Resour. Res., 37(4), 999-1013.

van Genuchten, M. T., and D. R. Nielsen (1985), On describing and predicting the hydraulic properties of unsaturated soils, Ann. Geophys., 3(5), 615-628.

Weill, S., E. Mouche, and J. Patin (2009), A generalized Richards equation for surface/subsurface flow modelling, J. Hydrol., 366(1-4), 9-20.

Winter, T. C., J. W. Harvey, O. L. Franke, and W. M. Alley (1998), Ground water and surface water: A single resource, Circ. 1139, U.S. Geol. Surv., Denver, Colo.

Woessner, W. W. (2000), Stream and fluvial plain ground water interactions: Rescaling hydrogeologic thought, Ground Water, 38(3), 423-429.

Yeh, P. J.-F., and E. A. B. Eltahir (2005), Representation of water table dynamics in a land surface scheme, Part I: Model development, J. Clim., 18(12), $1861-1880$.

M. Camporese, Dipartimento di Ingegneria Idraulica, Marittima, Ambientale e Geotecnica, Università degli Studi di Padova, I-35131 Padova, Italy. (camporese@idra.unipd.it)

C. Paniconi, Centre Eau, Terre et Environnement, Institut National de la Recherche Scientifique, Université du Québec, Quebec City, QC G1K 9A9, Canada. (claudio.paniconi@ete.inrs.ca)

S. Orlandini, Dipartimento di Ingegneria Meccanica e Civile, Università degli Studi di Modena e Reggio Emilia, I-41100 Modena, Italy. (stefano.orlandini@unimore.it)

M. Putti, Dipartimento di Metodi e Modelli Matematici per le Scienze Applicate, Università degli Studi di Padova, I-35131 Padova, Italy. (putti@dmsa.unipd.it) 